Award Number: DAMD17-01-1-0363

TITLE: Rapid Visual Assays of Oncogenic Aberrant ErbB Receptor Activation Using Fluorescence Microscopy.

PRINCIPAL INVESTIGATOR: Mitchell B. Berger

Mark A. Lemmon, Ph.D.

CONTRACTING ORGANIZATION: University of Pennsylvania

Philadelphia, Pennsylvania 19104-3246

REPORT DATE: July 2004

TYPE OF REPORT: Annual Summary

PREPARED FOR: U.S. Army Medical Research and Materiel Command Fort Detrick, Maryland 21702-5012

DISTRIBUTION STATEMENT: Approved for Public Release;

Distribution Unlimited

The views, opinions and/or findings contained in this report are those of the author(s) and should not be construed as an official Department of the Army position, policy or decision unless so designated by other documentation. 


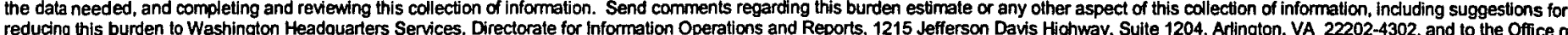
Management and Budget, Paperwork Reduction Project (0704-0188). Washington, DC 20503
1. AGENCY USE ONLY
2. REPORT DATE 3. REPORT TYPE AND DATES COVERED
(Leave blank)
July 2004 Annual Summary
(1 Jul 01-30 Jun 04)

4. TITLE AND SUBTITLE

Rapid Visual Assays of Oncogenic Aberrant ErbB Receptor

Activation Using Fluorescence Microscopy

5. FUNDING NUMBERS

DAMD17-01-1-0363

\section{AUTHOR(S)}

Mitchell B. Berger

Mark A. Lemmon, Ph.D.

\section{PERFORMING ORGANIZATION NAME(S) AND ADDRESS(ES)}

University of Pennsylvania

Philadelphia, Pennsylvania 19104-3246

8. PERFORMING ORGANIZATION REPORT NUMBER

E-Mail: mberger@mail.med.upenn.edu

\section{SPONSORING / MONITORING} AGENCY NAME(S) AND ADDRESS(ES)

U.S. Army Medical Research and Materiel Command Fort Detrick, Maryland 21702-5012
10. SPONSORING / MONITORING AGENCY REPORT NUMBER

\section{SUPPLEMENTARY NOTES}

12a. DISTRIBUTION / AVAILABILITY STATEMENT

Approved for Public Release; Distribution Unlimited

12b. DISTRIBUTION CODE

\section{ABSTRACT (Maximum 200 Words)}

The growth of cells in the body is closely regulated by peptide growth factors, which are detected by the cells via cell-surface receptors. Many human cancers of the breast, brain, etc., can develop if these receptors behave as if they sense the presence of growth factors when they should not. One particular family of receptors that has been heavily implicated in the development of human cancers is the ErbB receptor tyrosine kinase family, which includes both the EGF-Receptor and ErbB2/HER-2/neu - both of which are major targets for chemotherapeutic agents either in clinical use or in clinical trials. The physiologic outcome of both normal and oncogenic ErbB receptor activation depends on the ability of these receptors to form both homo- and heteromeric complexes, but the exact mechanism underlying the formation of these complexes is not well understood. We have used a variety of cell biological, biochemical and biophysical approaches to elucidate the nature of homo- versus heteromeric complexes in the ErbB receptor family.

\section{SUBJECT TERMS}

erbB, receptor, growth factor, homodimer, heterodimer

15. NUMBER OF PAGES

56

16. PRICE CODE

\section{LIMITATION OF ABSTRACT} OF THIS PAGE Unclassified
19. SECURITY CLASSIFICATION OF ABSTRACT Unclassified
Unlimited 


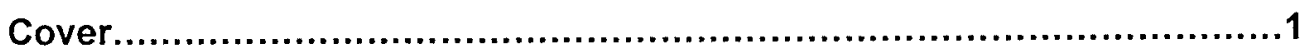

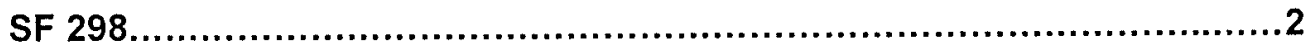

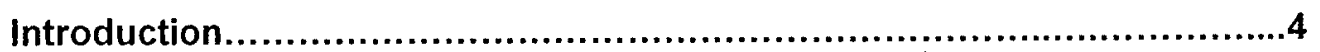

Body...........................................................................

Key Research Accomplishments............................................

Reportable Outcomes........................................................8

Conclusions.................................................................

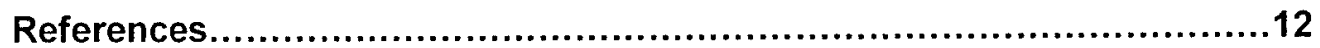

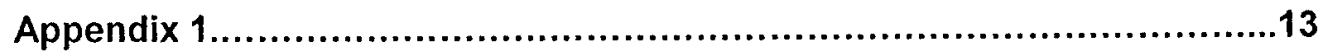

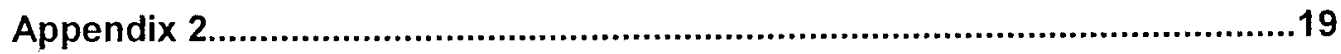




\section{INTRODUCTION}

The ErbB family of receptor tyrosine kinases has been shown to be clinically important in all stages of life, from development of the embryo and fetus to the maintenance of normal adult physiology $(1,2)$. However, these receptors have also been implicated in a vast array of human cancers, affecting a wide diversity of tissues and organs, including breast, prostate, brain and lung (3). The role of ErbB2 (also known as HER-2 or neu) has been extensively studied in breast cancer, leading to the development of Trastuzumab (Herceptin), an FDA approved humanized monoclonal anti-ErbB2 antibody, for use in chemotherapy against ErbB2-expressing breast cancer (4). However, this drug has been proven to have only limited clinical efficacy, thus underscoring the need for further research into the mechanisms of ErbB receptor signal transduction. In this project we used a wide variety of techniques from cell biology, biochemistry and biophysics in order to gain a better understanding of the mechanisms underlying the immediate-early steps in ErbB receptor activation, namely the formation of homo- and heteromeric complexes. Specifically, we showed that the extracellular domain of ErbB3 does not homodimerize upon binding its cognate ligand, neuregulin 1- $\beta 1$, even when anchored in the plasma membrane of a live cell. Under the same conditions, however, it readily heterooligomerizes with ErbB2, which does not bind any ligands and spontaneously homodimerizes only very weakly. The mitogenic potency of the ErbB3ErbB2 heterooligomer may therefore be explained, at least in part, by the homo- and heterointeraction characteristics of these receptors. We have also begun to probe the nature of the ErbB1 extracellular region homodimerization surface. We show that specific regions within this surface contribute significantly to the ability of the receptor to both bind ligand and adopt a structural conformation suitable for homodimerization. It is hoped that by elucidating more detailed information about these interactions at the structural and molecular level, we will be able to identify specific targets for drug discovery which will ultimately lead to improved chemotherapeutics for use in ErbB receptor-expressing cancers. 


\section{BODY}

The aim of this project has been to examine the nature of ErbB receptor homoand heterooligomers at the molecular level, in order to elucidate mechanisms underlying the ligand-induced oligomerization behavior of this important family of receptor tyrosine kinases. I discussed two different projects in my annual update and revised (and accepted) statement of work (SOW) last year that address these questions. The first project focused on the oligomeriztaion ErbB3, an interesting receptor in that it is the only member of the ErbB family reported to bind ligand but lack catalytic activity. The results of this project have been formally published (5), and the paper is included as an attachment (Appendix 1).

The results of this paper are briefly summarized in the following. We stably expressed full-length human ErbB1 (also known as the epidermal growth factor (EGF) receptor) and ErbB2 individually in Drosophila Schneider-2 (S2) cells, which express no endogenous human ErbB receptors and do not respond to stimulation by either human EGF or neuregulin 1- $\beta 1$ (NRG). We showed that receptor phosphorylation and activation of the Drosophila mitogen activate protein kinase (MAPK) pathway could only be effected by stimulation of the cells expressing ErbBl with EGF. We next generated chimerae containing the extracellular and transmembrane domains of ErbB3 and ErbB4 fused to the cytoplasmic regions of ErbB1, known as ErbB3/ErbB1 and ErbB4/ErbB1. As the kinase domain of ErbB1 must dimerize in order to be catalytically active, we reasoned that NRG-induced homodimerization of these chimerae would result in phosphorylation of the chimera as well as activation of MAPK, indicating whether or not the extracellular region homodimerize upon ligand-binding. Our main question was whether the ErbB3/ErbB1 chimera would become activated upon binding NRG, and the ErbB4/ErbB 1 chimera was generated as a positive control, as prior biophysical work in our lab had demonstrated that the ErbB4 extracellular domain homooligomerizes strongly upon binding NRG (6). We stably expressed these chimerae (individually) in S2 cells and demonstrated that the receptors were properly oriented and expressed at the cell surface. We next found that NRG-stimulation led to robust receptor phosphorylation and MAPK activation only in the cells stably expressing the ErbB4/ErbB1 chimera, suggesting that ErbB3 does not indeed homodimerize when it binds its ligand. We then transiently expressed full-length ErbB2 in the ErbB3/ErbB1 stable cell-line and again stimulated with NRG. Transfection with a plasmid encoding for ErbB2, but not a control empty plasmid, causes the cells to respond to NRG-stimulation with receptor autophosphorylation and MAPK activation, indicating that while the ErbB3/ErbB1 chimera does not homodimerize, it readily undergoes ligand-induced heterooligomerization with ErbB2, similarly to the native ErbB3 protein.

The other project described in my annual update and SOW last year focused on the homodimerization surface of ErbB1. Three X-ray crystal structures of the ErbB1 extracellulardomain have been recently solved, and suggest a novel mechanism for EGFinduced ErbB1 homodimerization (7-9). We have used biophysical studies (specifically, ligand-binding measurements via surface plasmon resonance using a Biacore instrument, and homodimerization potentials using sedimentation equilibrium analysis in an analytical ultracentrifuge) of recombinant ErbB1 extracellular domains (wild-type and mutant versions) in order to study the energetic contributions of different regions of the 
homodimerization surface to ligand-binding and homodimerization. The chapter of my thesis detailing the results of these studies and interpretations is included as an attachment (Appendix 2). This project has been taken over by a new post-doctoral fellow in the lab, and the results of this study (including the work that I have accomplished) are currently in the process of being compiled into a manuscript for submission 


\section{KEY RESEARCH ACCOMPLISHMENTS}

- Completed study examining humàn ErbB ligand-induced signaling in Schneider 2 cell-lines stably expressing human ErbB1, ErbB2, ErbB3/ErbB1 chimera and ErbB4/ErbB1 chimera

- Performed MAPK and receptor activation experiments in stable S2 cell-lines, demonstrating lack of ErbB3 homodimerization upon binding NRG, but robust and productive heterooligomerization of NRG-bound ErbB3/ErbB1 and ErbB2

- Analyzed ligand-binding and homodimerization characteristics of various mutants of soluble ErbB1 extracellular domain 


\section{REPORTABLE OUTCOMES}

This research has resulted in the generation of a set of Drosophila cells expressing various functional human ErbB receptors and receptor chimerae.

This research has resulted in the generation of mutants of the ErbB1 extracellular domain that have varied effects on ligand-binding and homodimerization.

The work supported by this research resulted in the completion of a doctoral thesis, entitled "Mechanisms of ErbB Receptor Oligomerization." The completion of this work and thesis were recognized with the degree of Doctor of Philosophy bestowed upon the author in May, 2004, along with the Saul Winegrad, M.D. Award for Outstanding Dissertation. The doctoral thesis, in its entirety, is available upon request.

Work supported by this research resulted in the following publication: Berger, M. B., Mendrola, J. M. and Lemmon, M. A., "ErbB3/HER3 does not homodimerize upon neuregulin binding at the cell surface," FEBS Letters (2004) 569: 332-336. 


\section{CONCLUSIONS}

The ErbB receptors play important roles in human development and the pathogenesis of a large number of human diseases, especially cancers. While there are many drugs being developed to block the activity of the receptors in disease states, they are relatively primitive in design, typically being antibodies targeted to the extracellulardomains or kinase inhibitors (10-11). While it is clear that the cause of these ailments is generally receptor overexpression, the actual events involved in the activation of the receptors is still largely unknown. Our goal has been to gain a better understanding of the mechanisms driving the homo- and hetero-oligomerization of the ErbB receptors so as to be able to design smarter drugs that specifically target the aberrant activity of given receptors, while minimizing side-effects and damage to healthy tissue.

\section{ErbB3 Homodimerization}

Shortly after its identification, it became clear that ErbB3 contains an impaired kinase domain (12-13). It is therefore understood that this receptor is an obligate heterodimerization partner in functional receptor signaling complexes. However, it has been controversial as to whether the receptor homodimerizes in response to binding NRGs.

Our data indicate that ErbB3 does not homodimerize when it binds ligand, at least not in an arrangement that can activate the ErbB1 kinase domain. This provides an explanation as to why ErbB2-ErbB3 heterodimers appear to be so ubiquitous and potent compared with other heteromeric ErbB receptor complexes. As ErbB3 cannot homodimerize (and nor does ErbB2), any ligand-bound receptor will be driven to form heterodimers. As was shown by X-ray crystallography, the ErbB2 extracellulardomain exists in a constitutively extended conformation with its dimerization arm solvent exposed, an essentially pre-activated form waiting to heterodimerize with another receptor (14-15). Therefore, if the two receptors are coexpressed in a cell, even low levels of ErbB3 activation will lead to the formation of activated ErbB2-ErbB3 heterodimers. These two receptors can recruit a large host of signaling effectors that mediate mitogenic and survival responses, so aberrant formation and activation of the heterodimer can readily result in transformation (16-17). In contrast, both ErbB1 and ErbB4 demonstrate robust homodimerization in response to their ligands, so heterodimerization will only occur at the expense of homomeric interactions, making it a much rarer event.

\section{ErbB1 Homodimer Interface}

The recent crystal structures of the ErbB1 extracellulardomain have provided a wealth of information about the mechanism by which growth factors induce activation of the receptor (7-9). However, as these structures are static pictures of discrete conformations, we can only surmise the dynamic events by extrapolation. The biophysical studies of the structure-based mutants have allowed us to generate the framework for a more detailed model of ErbB1 homodimerization including structural and energetic considerations. 
The existing crystal structures highlight a number of regions that can be targeted to block homodimerization, and perhaps heterodimerization. An obvious choice would be the dimerization arm, as antibodies or small molecules that bind to this loop could very clearly interfere with inter-receptor contacts and thereby block dimerization and activation. Another region is the ligand-binding interface involving domains I and III. It is easy to imagine that a molecule could be designed to bind tightly to the binding site in domain III, but be so large that it would inhibit the close approximation of domain I necessary to disrupt the intramolecular tether.

The study of the ErbBl extracellulardomain mutants indicate different regions of interest. While the region at the N-terminus of domain II surrounding GIn ${ }^{194}$ was shown to make inter-receptor contacts (9), this area does not seem to be important for either ligand-binding or homodimerization. However, it should be noted that the protein in our study only had a single point mutation (altering the only polar group in this region), whereas Garrett and colleagues identified a larger region as the binding interface. Mutation of a larger subset of residues in this area might therefore reveal a contribution of this region to receptor activation. Alternatively, different amino acid substitutions, e.g., replacement with larger, bulkier residues rather than alanine, might be necessary to inhibit contributions to dimerization from this region.

Domain IV has also been implicated as a source of interaction energy between the receptors (18-19). However, both sets of mutations that we have generated in this region have served to enhance the affinity of the extracellulardomain for growth factors without impact on homodimerization. We therefore argue that domain IV is unlikely to play a strong role in homodimerization. This is also supported by the fact that domain IV was largely disordered in the crystal structure of the dimeric complex of EGF with the fulllength ErbB1 extracellulardomain, indicating that this region is not involved in a large set of stabilizing interactions (8). Further studies of this domain are necessary to fully determine the role it plays in activation of the receptor. For example, mutations in sections of domain IV distant from the site of interaction with the intramolecular tether would be instructive. Also, quantitative analysis of a domain IV-deleted form of the extracellular domain are needed. Additionally, our current data indicate that domain IV could serve as a target for potent drugs to block the activation of ErbB1 if agents could be developed that enhance the affinity for the dimerization arm to the binding pocket in domain IV. These drugs would function by diminishing the ability of ligand-stimulation or overexpression to induce extracellulardomain extension and exposure of the dimerization arms, and hence, result in decreased activation. Greene and colleagues have also suggested that this region is indeed a useful target for blocking ErbB receptor oligomerization and activation (18). The data from this study indicate that the domain IV-derived peptides bind quite weakly to the receptor extracellulardomains. However, if they do bind, they may inhibit activation by sterically inhibiting receptor oligomerization, rather than through alterations of ligand-induced extracellulardomain conformational changes.

Interestingly, the loop at the C-terminus of domain II containing $\mathrm{Asp}^{279}$ and $\mathrm{His}^{280}$ appears to be extremely important in mediating conformational changes associated with ligand binding and homodimerization. Mutation of these two residues to Ala results in a significant reduction of affinity for growth factor and a substantially diminished ability to homodimerize, even though this extracellulardomain binds to the ligands more rapidly 
than the wild-type protein. We hypothesize that this region is altered in conformation as the receptor samples the available array of configurations, and that by mutating these residues, we have reduced the number of available conformations, restricting the ability of the protein to achieve the optimal structure for activation. The importance of this region is also supported by studies of $\mathrm{mAb} 806$, a monoclonal antibody which binds to a conformationally-sensitive epitope in this region (20-22). Further characterization of this region and its role in ligand-binding and receptor dimerization could lead to new drugs that block the ability of the receptor to become activated. 


\section{REFERENCES}

1. Alroy, I. and Yarden, Y. (1997) FEBS Lett 410, 83-6.

2. Gusterson, B. Cowley, G., Smith, J. A., and Ozanne, B. (1994) Cell Biol Int Rep 8, 649-58.

3. Klapper, L. N., Kirschbaum, M. H., Sela, M., and Yarden, Y. (2000) Adv Cancer Res 77, 25-79.

4. Shak, S. (1999) Semin Oncol 26, 71-7.

5. Berger, M. B., Mendrola, J. M, and Lemmon, M.A. (2004) FEBS Lett 569, 332-336.

6. Ferguson, K. M., Darling, P. J., Mohan, M. J., Macatee, T. L. and Lemmon, M. A. (2000) EMBO J 19, 4632-43.

7. Ferguson, K. M., Berger, M. B., Mendrola, J. M., Cho, H-S., Leahy, D. J. and Lemmon, M. A. (2003) Mol Cell 11, 507-17.

8. Ogiso, H., Ishitani, R., Nureki, O., Fukai, S., Yamanaka, M., Kim, J. H., Saito, K., Sakamoto, A., Inoue, M., Shirouzu, M., and Yokoyama, S. (2002) Cell 110, 775-87.

9. Garrett, T. P. McKern, N. M., Lou, M., Elleman, T. C., Lovrecz, G. O., Zhu, H. J., Walker, F., Frenkel, M. J., Hoyne, P. A., Jorissen, R. N., Nice, E. C., Burgess, A. W. and Ward, C. W. (2002) Cell 110, 763-73.

10. Normanno, N., Maiello, M. R., and De Luca, A. (2003) J. Cell. Physiol. 194, 13-19.

11. Ranson, M., and Sliwkowski, M. X. (2002) Oncology 63 Suppl. 1, 17-24.

12. Guy, P. M., Platko, J. V., Cantley, L. C., Cerione, R. A., and Carraway, K. L., 3rd. (1994) PNAS U. S. A. 91, 8132-8136.

13. Sierke, S. L., Cheng, K., Kim, H. H., and Koland, J. G. (1997) Biochem J 322 (Pt 3), 757-763.

14. Cho, H. S., Mason, K., Ramyar, K. X., Stanley, A. M., Gabelli, S. B., Denney, D. W., Jr., and Leahy, D. J. (2003) Nature 421, 756-760.

15. Garrett, T. P., McKern, N. M., Lou, M., Elleman, T. C., Adams, T. E., Lovrecz, G. O., Kofler, M., Jorissen, R. N., Nice, E. C., Burgess, A. W., and Ward, C. W. (2003) Mol Cell 11, 495-505.

16. Citri, A., Skaria, K. B., and Yarden, Y. (2003) Exp Cell Res 284, 54-65.

17. Holbro, T., Civenni, G., and Hynes, N. E. (2003) Exp Cell Res 284, 99-110.

18. Berezov, A., Chen, J., Liu, Q., Zhang, H. T., Greene, M. I., and Murali, R. (2002) J

Biol Chem 277, 28330-28339.

19. Saxon, M. L., and Lee, D. C. (1999) J Biol Chem 274, 28356-28362.

20. Johns, T. G., Stockert, E., Ritter, G., Jungbluth, A. A., Huang, H. J., Cavenee, W. K., Smyth, F. E., Hall, C. M., Watson, N., Nice, E. C., Gullick, W. J., Old, L. J., Burgess, A. W., and Scott, A. M. (2002) Int J Cancer 98, 398-408.

21. Jungbluth, A. A., Stockert, E., Huang, H. J., Collins, V. P., Coplan, K., Iversen, K., Kolb, D., Johns, T. J., Scott, A. M., Gullick, W. J., Ritter, G., Cohen, L., Scanlan, M. J., Cavenee, W. K., and Old, L. J. (2003) PNAS U. S. A. 100, 639-644.

22. Luwor, R. B., Johns, T. G., Murone, C., Huang, H. J., Cavenee, W. K., Ritter, G., Old, L. J., Burgess, A. W., and Scott, A. M. (2001) Cancer Res 61, 5355-5361. 


\section{APPENDICES}

APPENDIX 1 - Reprint of Berger, et al. (2004) FEBS Lett 569: 332-336.

Note: At time of preparing this final summary, this paper has been accepted for publication and given a citation reference, but this issue of FEBS Lett is not yet in press, so I am including a copy of the "Uncorrected Proof" available as a downloadable PDF from the publisher's website.) 
2

\title{
ErbB3/HER3 does not homodimerize upon neuregulin binding at the cell surface
}

\author{
Mitchell B. Berger ${ }^{\mathrm{a}, \mathrm{b}}$, Jeannine M. Mendrola ${ }^{\mathrm{a}}$, Mark A. Lemmon ${ }^{\mathrm{a}, \mathrm{b}, *}$ \\ "Department of Biochemistry and Biophysics, University of Pentsyltania School of Medicine, Philadelphia, PA 19104-6059, USA \\ ${ }^{b}$ Graduate Group in Biochemistry' and Molecular Biophysics, University of Pennsyluania School of Medicine, Philadelphia, PA 19104-6059, USA
}

Received 19 April 2004; revised 3 June 2004; accepted 7 June 2004

Available online

Edited by Veli-Pekka Lehto

10 Abstract To understand signaling by the neuregulin (NRG)

11 receptor ErbB3/HER3, it is important to know whether ErbB3

12 forms homodimers upon ligand binding. Previous biophysical

13 studies suggest that the ErbB3 extracellular region remains

14 monomeric when bound to NRG. We used a chimeric receptor

15 approach to address this question in living cells, fusing the

16 extracellular region of ErbB3 to the kinase-active intracellular

17 domain of ErbB1. The ErbB3/ErbB1 chimera responded to NRG

18 only if ErbB2 was co-expressed in the same cells, whereas an

19 ErbB4/ErbB1 chimera responded without ErbB2. We, therefore,

20 suggest that ErbB3 is an obligate heterodimerization partner

21 because of its inability to homodimerize.

(C) 2004 Published by Elsevier B.V. on behalf of the Federation of European Biochemical Societies.

Keyw'ords: Heterodimer; epidermal growth factor; Receptor; Tyrosine kinase; Signalling

\section{Introduction}

The epidermal growth factor (EGF) receptor, or ErbB,

29 family of receptor tyrosine kinases play important roles in

30 normal embryonic development, and their aberrant signaling is

31 associated with human cancers [1,2]. There are four members

32 of the family: the EGF receptor itself (EGFR or ErbB1),

33 ErbB2 (also known as HER2 or Neu), ErbB3 (HER3) and

34 ErbB4 (HER4). Each has a large ( 620 amino acid) extra-

35 cellular ligand-binding region, a single transmembrane $\alpha$-helix,

36 and an intracellular region containing the tyrosine kinase do-

37 main plus regulatory sequences. ErbB1/EGFR is activated

38 directly by multiple ligands, which promote homodimerization

39 and autophosphorylation of the receptor [3]. ErbB4 appears to

40 be regulated (in part) in a similar manner, but by neuregulins

41 (NRGs) rather than EGF receptor agonists [4]. By contrast,

42 ErbB2 has no known direct extracellular ligands, and ErbB3

43 binds NRGs but appears to have a non-functional tyrosine

44 kinase domain [5-8].

45 The ErbB receptors form a network of homo- and hetero46 dimers [1,9]. ErbB2 can only be regulated indirectly, and is 47 thought to be the preferred heterodimerization partner for 48 other ErbB receptors [10]. ErbB3, on the other hand, must 49 associate with an ErbB family member that has an active ty-

\footnotetext{
Corresponding author. Fax: + 1-215-573-4764.

E-mail address: mlemmon@mail.med.upenn.edu (M.A. Lemmon).
}

rosine kinase in order to respond to its own NRG binding. It is thought that the NRG-induced ErbB3/ErbB2 heterodimer is among the most potent mitogenic signaling complexes in the ErbB network [8,11-13]. However, the molecular mechanism for activation of ErbB2 and ErbB3 through NRG-induced hetero-oligomerization is not clear. Whereas other receptor extracellular regions dimerize upon ligand binding, no study of the ErbB3 extracellular region has detected dimerization upon NRG binding [14-17]. The ErbB2 extracellular region also fails to homodimerize even at very high concentrations $[15,18,19]$.

It is important to know whether or not intact ErbB3 homodimerizes on NRG binding in order to understand how ErbB2/ErbB3 hetero-oligomers signal. If ErbB3 is truly kinaseinactive, and ErbB receptor activation involves trans-phosphorylation of receptors, it is not clear how ErbB2 can become either activated or phosphorylated within a simple ErbB2/ ErbB3 heterodimer. This difficulty could be resolved if signaling occurs in the context of a higher-order ErbB2/ErbB3 hetero-oligomer, such as a heterotetramer, and it has been suggested that such heterotetramers might be 'nucleated' by NRG-induced ErbB3 homodimerization $[3,20]$. To test this hypothesis in a cellular context, we analyzed signaling by ErbB3/ErbB1 and ErbB4/ErbB1 chimerae to determine whether NRGs can promote ErbB3 homodimerization at the cell surface. Under conditions identical to those that promote robust activation of the ErbB4 chimera, we find that NRGs cannot induce activation of the ErbB3 chimera. Our findings argue that NRG does not promote ErbB3 homodimerization at the cell surface, and have important implications for understanding the mechanism of signaling through ErbB3/ErbB2 hetero-oligomers.

\section{Materials and Methods}

2.1. Expression constructs

Full-length human ErbB1 and ErbB2 were subcloned into Kpnl/Notl digested pAc5.1/V5-HisA (Invitrogen Corporation, Carlsbad, CA). Constructs encoding chimerae with the extracellular region plus transmembrane domain of either ErbB3 or ErbB4 fused to the entire cytoplasmic sequence of ErbBI (ErbB3/ErbB1 or ErbB4/ErbB1) were generated by four-primer PCR. In ErbB3/ErbB1, the ErbB3 fragment extends through Trp647. In ErbB4/ErbB1, the ErbB4 fragment extends through Val675. The ErbB1 fragment begins at Arg645 in both cases.

\subsection{Cell culture}

Schneider-2 (S2) Drosophila melanogaster cells (Invitrogen) were grown at $24{ }^{\circ} \mathrm{C}$ in complete Schneider's Medium (Sigma-Aldrich, St. Louis, MO), containing penicillin/streptomycin $\left(50 \mathrm{U} \mathrm{ml}^{-1} / 50 \mu \mathrm{g}\right.$ 
$\mathrm{ml}^{-1}$ ), and gentamicin (50 $\left.\mu \mathrm{g} / \mathrm{ml}\right)$ (GibcoBRL, Rockville, MD), supplemented with $10 \%$ heat-inactivated fetal bovine serum (FBS) (HyClone, Logan, UT)

98 2.3. Stable cell-lines

99 S2 cells were transfected with $20 \mu \mathrm{g}$ DNA (19 $\mu \mathrm{g}$ desired expression 100 construct plus $1 \mathrm{~g}$ pCoHygro selection vector (Invitrogen)) using the

101 calcium phosphate method (Invitrogen). After approximately 3 weeks

102 of selection, pools of cells resistant to $300 \mu \mathrm{g} / \mathrm{ml} \mathrm{Hygromycin} \mathrm{B} \mathrm{were}$

103 expanded and screened for expression by Western blotting and flow

104 cytometry. All stably expressing cell-pools were maintained in com-

105 plete Schneider's Medium supplemented with $10 \%$ FBS and $300 \mu \mathrm{g} / \mathrm{ml}$

106 Hygromycin B.

107 2.4. Antihodies

108 Western blots were probed with anti-ErbB1 antibody Ab-15, anti109 ErbB2 antibody Ab-8 (NeoMarkers, Freemont. CA), anti-phospho-

110 MAP Kinase antibody 9101 (Cell Signaling Technology, Beverly, MA),

111 anti-MAP Kinase antibody M 5670 (Sigma-Aldrich) and anti-phos-

112 pho-tyrosine antibody PY20 (Zymed Laboratories, South San Fran-

113 cisco, CA). Flow cytometry was performed with $R$-phycoerythrin $(R-$

114 PE)-conjugated anti-EGFR, $R$-PE-conjugated anti-HER-2/Neu anti-

115 bodies, $R$-PE-conjugated secondary antibodies (rat anti-mouse $\operatorname{IgG}_{2 \mathrm{~A}-\mathrm{b}}$

116 and rat anti-mouse $\mathrm{IgG}_{1}$ ) (BD Biosciences, Franklin Lakes, NJ), anti-

117 ErbB3 antibody Ab-4, and anti-ErbB4 antibody Ab-1 (NeoMarkers).

\section{2.5. Flow cytometry}

119 For analysis of ErbB1 and ErbB2 expression, cells were incubated

120 for $30 \mathrm{~min}$ on ice with PE-conjugated antibodies, and then diluted to 121 approximately $500 \mathrm{~L}$ in PBS with $2 \%$ FBS. For ErbB3 and ErbB4

122 analysis, cells were incubated on ice for $30 \mathrm{~min}$ with $5 \mu \mathrm{g}$ primary 123 antibodies, washed with ice-cold PBS/FBS, and subsequently incu-

124 bated for $30 \mathrm{~min}$ on ice with $R$-PE-conjugated secondary antibodies

$125(1: 50(\mathrm{v} / \mathrm{v}))$. Flow cytometry was performed using a FACScan flow

126 cytometer (BD Biosciences).

\section{3. Results}

Since the tyrosine kinase domain of ErbB3 appears to be

\subsection{Receptor phosphorylation and MAPK actitation experiments} Cells were harvested, washed with PBS, and serum-starved overnight in complete Schneider's medium supplemented with $0.5 \%$ FBS (staration medium). Cells were then stimulated on ice (for receptor phosphorylation) or at room temperature (for MAP kinase (MAPK) phosphorylation studies) for $10 \mathrm{~min}$ with $100 \mathrm{ng} / \mathrm{ml} \mathrm{EGF} \mathrm{(EGF)} \mathrm{(In-}$ ergen, Purchase, NY) or human NRGI- $\beta 1$ EGF domain (R\&D Systems. Minneapolis, MN) or were left untreated. The cells were washed with ice-cold PBS and lysed in RIPA buffer ( $25 \mathrm{mM}$ Tris- $\mathrm{HCl}$, pH 7.5 . $150 \mathrm{mM} \mathrm{NaCl}, 1 \%$ Triton X-100, 1\% sodium deoxycholate, 0.1\% SDS,

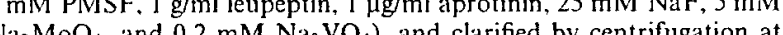
$14000 \mathrm{rpm}$ for $10 \mathrm{~min}$ at $4^{\circ} \mathrm{C}$. Boiled samples of equal protein levels re then subjected to Western blotting analysis with the indicated antibodies, followed by horseradish peroxidase-conjugated secondary antibodies, and were detected using chemiluminescence. catalytically impaired or inactive [5-7], ligand-induced dimerization of this receptor cannot be followed by directly analyzing its autophosphosphorylation. To circumvent this problem, we generated a chimera with the extracellular region plus transmembrane domain of ErbB3 fused to the cytoplasmic region of EGFR. This chimera will have the NRG-binding properties of ErbB3, yet its intracellular region should be capable of dimerization-dependent kinase activation as seen with EGFR. If NRG-binding does induce dimerization of the ErbB3 extracellular region in a cellular context, this should be evidenced by ligand-induced autophosphorylation of the ErbB3/ErbB1 chimera and resulting MAPK activation. As a positive control, we also generated a chimera in which the extracellular region is instead derived from ErbB4. Previous

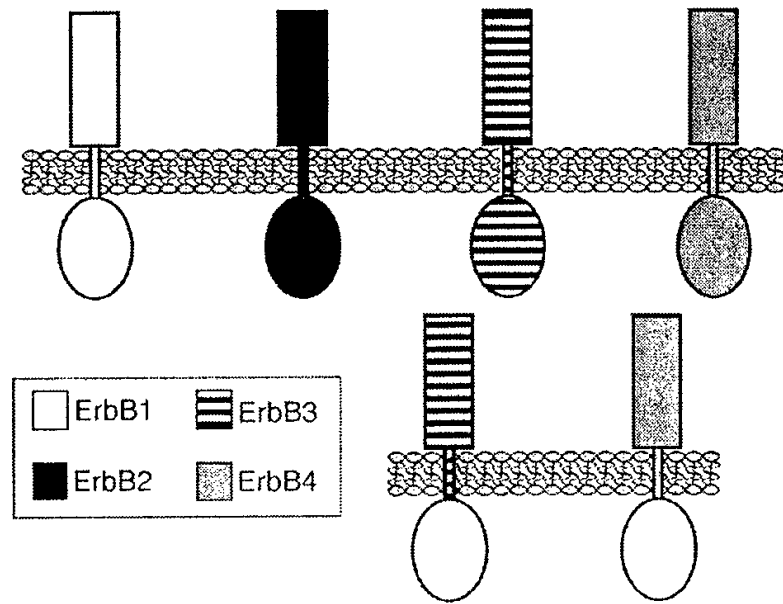

Fig. 1. Schematic representation of ErbB receptors and chimerae.

work has shown that the extracellular region of ErbB4 oligomerizes readily upon NRG binding [15], so the ErbB4/ErbB1 chimera should certainly show NRG-regulated autophosphorylation and activation. A schematic representation of the ErbB receptors and the chimerae are shown in Fig. 1.

\subsection{Signaling by human ErbB receptors in Drosophila Schneider-2 cells}

We used the Drosophila melanogaster Schneider-2 (S2) cellline as a null background for mammalian ErbB proteins. Insect cell-lines have previously been used as cellular backgrounds for a number of studies of the human ErbB receptors $[7,16,21-23]$.

We first tested the utility of $S 2$ cells by generating cells that stably overexpress human ErbB1 or ErbB2. As shown in Fig. 2, human ErbB1 expressed in S2 cells was tyrosine autophosphorylated in response to EGF (but not NRG) treatment. In addition, robust EGF-induced activation (phosphorylation) of Drosophila rolled/MAPK could be detected by immunoblotting with anti-phospho-MAPK antibodies. These responses were EGF-specific, and were only found in ErbB1expressing S2 cells. No similar responses were detected upon EGF or NRG treatment of parental S2 cells or cells expressing human ErbB2.

\subsection{NRG efficiently activates an ErbB4/ErbBI chimera, but not an ErbB3/ErbBI chimera}

Having established that human ErbB1 can signal in S2 cells, we next generated cell-lines that stably express either the ErbB3/ErbB1 or ErbB4/ErbB1 chimera depicted in Fig. 1. We verified that that both chimerae were expressed at the cell surface using flow cytometry (Fig. 3), indicating that our chimeric receptors are correctly folded and processed - so that differential accessibility to extracellular ligand can be ruled out in interpreting any differences in their signaling. Comparative studies of human breast cancer cell lines with reported numbers of NRG-binding sites [24] suggested that our chimerae are expressed at $10^{4}-10^{5}$ copies per cell, with the ErbB3/ErbB1 chimera expressed at 2-5 fold higher levels than the ErbB4/ ErbBl chimera.

We analyzed the ability of NRG to stimulate autophosphorylation of the ErbB3/ErbB1 and ErbB4/ErbB1 chimerae 


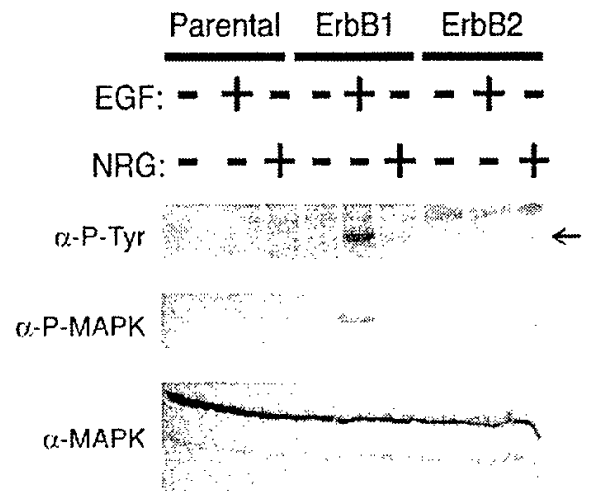

Fig. 2. Ligand-induced activation of human ErbB receptors in Drosophila $\mathrm{S} 2$ cells. Receptor autophosphorylation and MAPK activation were analyzed by immunoblotting whole-cell lysates from parental. ErbB1-expressing. and ErbB2-expressing S2 cells after treatment with human EGF or NRG. The primary antibodies used for Western blotting are marked at left, and recognize phospho-tyrosine ( $x$-P-Tyr) (top blot), phosphorylated MAPK ( $x$-P-MAPK) (middle blot), and pan-MAPK ( $x$-MAPK) (lower blot). The arrow at right in the top blot marks the size of the exogenous ErbB receptor bands to distinguish from endogenous Drosophila phospho-lyrosine containing proteins.
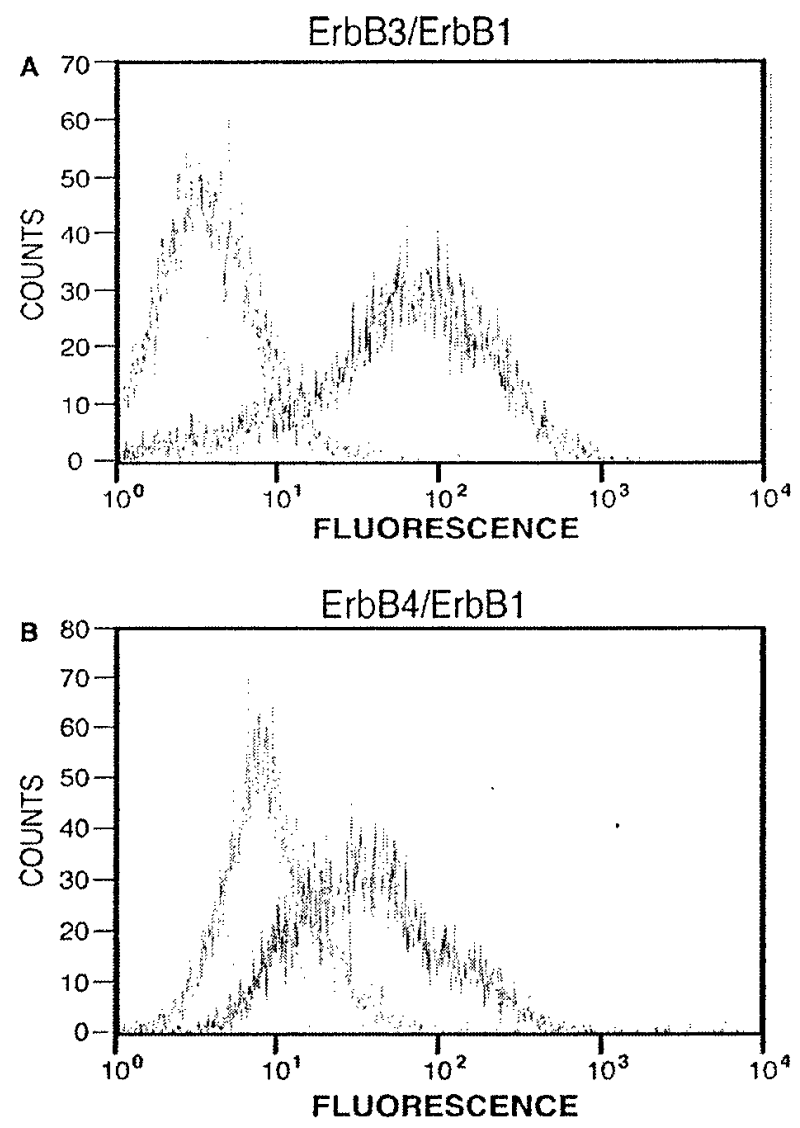

Fig. 3. Cell-surface expression of ErbB3/ErbB1 and ErbB4/ErbB1 chimerae. Expression of the ErbB3/ErbB1 (A) and ErbB4/ErbB1 (B) chimerae on the cell surface, analyzed by flow cytometry. The solid gray traces (with peaks shaded gray) represent data from parental S2 cells treated with the primary and secondary antibodies, while the black traces represent data from the stable cell-lines analyzed in the same fashion. The marked right-shifts in each case demonstrate that both chimerae are expressed appropriately at the cell surface. 10000 cells were analyzed for each FACS analysis.
A

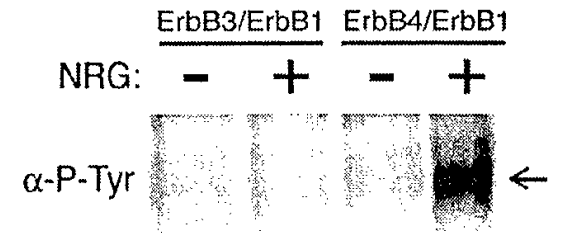

$\alpha$-ErbB1

(endo)

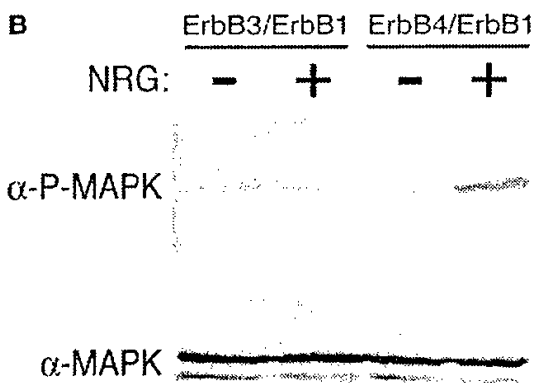

Fig. 4. Analysis of signaling by ErbB3/ErbBl and ErbB4/ErbBl chimerae in S2 cells. (A) S2 cells stably expressing the ErbB3/ErbB1 and ErbB4/ErbB1 chimera were left unstimulated or treated with NRG on ice. Receptor autophosphorylation was analyzed by immunoblotting with anti-phosphotyrosine ( $\alpha-\mathrm{P}-\mathrm{Tyr}$ ) antibody (upper blot). An arrow highlights the bands corresponding to the human ErbB receptor chimerae. Chimera expression was confirmed by Western blotting with an antibody specific for the ErbBI intracellular domain ( $x$-ErbBI endo) antibody (lower blot). (B) Stable cell pools expressing ErbB3/ErbBl or ErbB4/ErbB1 were treated for $10 \mathrm{~min}$ at room-temperature with no growth factor $(-)$ or with NRG $(+)$. Upper blot: detection of activated MAPK ( $x$-P-MAPK). Lower blot: detection of total MAPK loaded $(x-$ MAPK).

and resulting MAPK activation. As shown in Fig. 4A, robust NRG-induced autophosphorylation was detected in cells expressing the ErbB4/ErbB1 chimera, but no response was observed with the ErbB3/ErbB 1 chimera. Similarly, NRG promoted strong MAPK phosphorylation in S2 cells expressing the ErbB4/ErbB1 chimera but not those expressing ErbB3/ ErbB1 (Fig. 4B). Thus, the ErbB3/ErbBl chimera is not sensitive to ligand stimulation despite that fact that it is well expressed at the cell surface (Fig. 3A), and that an identically designed ErbB4/ErbB1 chimera signals robustly. Together with our inability to detect dimers of the ErbB3 extracellular region in biophysical studies [15], these results argue that ErbB3 does not homodimerize when it binds NRG.

\subsection{The ErbB3/ErbBI chimera form a functional heteromeric $N R G$ receptor with ErbB2}

To rule out the possibility that the ErbB3/ErbB1 chimera is non-functional for some reason not controlled for in our investigation, we asked whether it could form an active signaling complex with human ErbB2. As mentioned in Section 1, ligand-induced active ErbB3/ErbB2 heterodimers are thought to be potently mitogenic (and oncogenic). Alone, neither ErbB2 nor ErbB3 can activate signaling cascades upon NRG-stimulation. However, coexpression of ErbB2 with ErbB3 generates 

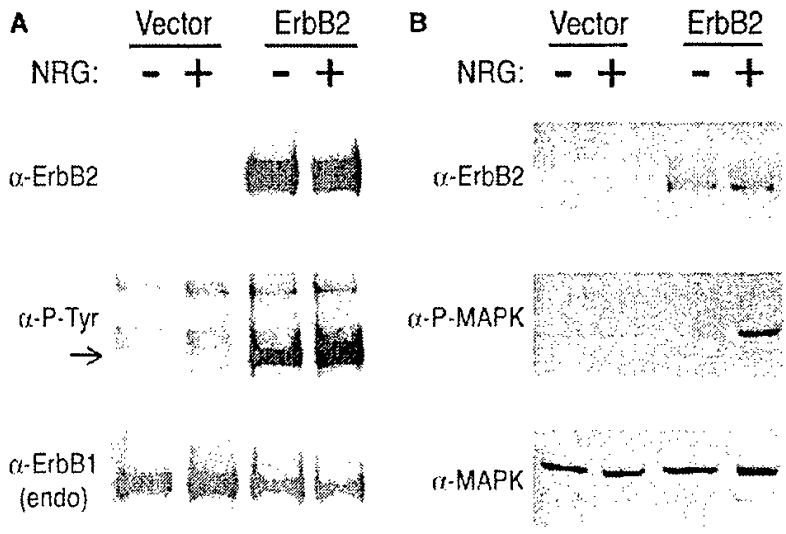

Fig. 5. Transient expression of ErbB2 reconstitutes NRG signaling in S2 cells expressing the ErbB3/ErbB1 chimera. (A) S2 cells expressing the ErbB3/ErbBl chimera were transiently transfected with human ErbB2 and were stimulated with NRG. Immunoblotting of whole-cell lysates was performed with an anti-ErbB2 antibody (upper blot) antiphosphotyrosine (middle blot). and chimera expression (lower blot) was detected with an anti-ErbBl endodomain-specific antibody $(x-$ ErbB1 endo). (B) MAPK activation was analyzed by immunoblotting of whole-cell lysates of ErbB3/ErbBI-expressing cells transiently transfected with control or ErbB2 vectors. Upper blot: ErbB2 expression $(\alpha$-ErbB2). Middle blot: activated MAPK ( $x$-P-MAPK). Lower blot: total MAPK loaded ( $\alpha$-MAPK).

a potent functional NRG receptor $[11,25,26]$. If this cooperation results primarily from extracellular interactions, we anticipate that coexpression of ErbB2 with the ErbB3/ErbB1 chimera in $\mathrm{S} 2$ cells should also reconstitute NRG signaling.

We transiently transfected ErbB3/ErbB1-expressing S2 cells with a plasmid that drives expression of full-length human ErbB2. As shown in Fig. 5, although transient overexpression of ErbB2 in these cells resulted in high levels of basal autophosphorylation as described by others [26,27], a slight NRGinduced enhancement of receptor autophosphorylation can be discerned in the cells co-expressing ErbB2 and the ErbB3/ ErbB1 chimera. More convincingly, Fig. 5B shows that, whereas NRG does not promote MAPK activation in parental or ErbB2-expressing S2 cells (see Fig. 2) or the ErbB3/ErbB1 chimera alone, it does induce a robust increase in phosphoMAPK levels when both proteins are expressed. These results argue that the ErbB3/ErbBl chimera can respond to NRG. However, like wild-type ErbB3, it is only competent to signal when expressed alongside another ErbB receptor with which it can form heteromeric complexes. Interestingly, this appears to be a property of ErbB3 whether its kinase domain is active (as in our ErbB3/ErbB1 chimera) or impaired (as in wild-type ErbB3). We, therefore, suggest that the unusual signaling properties of ErbB3 arise less from its reported inability to function as a tyrosine kinase than from its ability to form ligand-induced homodimers.

249 A key question in ErbB receptor signaling is whether ligand 250 binding causes ErbB2 and ErbB3 to form heterodimers or 251 larger oligomers. If ErbB3 is kinase-inactive, and, therefore, 252 cannot phosphorylate ErbB2 directly, it is difficult to see how

253 NRG could activate ErbB2 in the context of an ErbB2/ErbB3 heterodimer. This consideration has led to the suggestion that higher order hetero-oligomers must form $[3,15,28]$, perhaps nucleated by NRG-induced ErbB3 homodimerization, allowing ErbB2 molecules to phosphorylate one another. Here, we provide evidence suggesting that NRG does not induce ErbB3 homodimerization at the cell surface, supporting previous studies employing isolated extracellular domains [14-17]. These findings argue against the hypothesis that NRG induces large ErbB2/ErbB3 hetero-oligomers, and together with recent structural studies [29] are more consistent with the possibility that ErbB3 does directly activate ErbB2 in the context of NRG-induced ErbB2/ErbB3 heterodimers.

How might ErbB3 trans-activate ErbB2 in such a heterodimer? One possibility is that it does possess significant (but low level) kinase activity, and can trans-phosphorylate ErbB2 in the context of a heterodimer. The initial suggestion that the ErbB3 kinase domain is impaired was sequence-based [30,31], and was supported by subsequent studies of the intact protein [5-7] and its isolated kinase domain [6] (although none conclusively demonstrated an absence of activity). Guy et al. [5] reported that the tyrosine kinase activity of full-length insect cell-expressed ErbB3 is at least 100-fold weaker than that for ErbB1 or ErbB2. ErbB3 autophosphorylation and substrate phosphorylation was readily detectable in these studies, but its insensitivity to NRG treatment led to the interpretation that ErbB3 alone was not responsible. However, if NRG does not promote ErbB3 homodimerization - as our studies and previous biophysical analyses suggest - then such NRG activation would not be expected. Thus, a possible interpretation of earlier phosphorylation studies is that ErbB3 does in fact have a low (but nonetheless detectable) level of kinase activity, but that it is not activated (through homodimerization) by NRG binding to the extracellular region. Caution should, therefore, be exercised in assuming the ErbB3 is truly 'kinase-dead'. Indeed, consistent with a requirement for ErbB3 kinase activity, Wallasch et al. [26] found that mutation of a critical lysine in the ATP binding site of ErbB3 significantly reduces the extent of NRG-induced ErbB2 phosphorylation in cells expressing both ErbB2 and the mutated (or wild-type) ErbB3. These findings are clearly consistent with the possibility that ErbB3 directly phosphorylates ErbB2 in the context of a NRG-induced ErbB2/ErbB3 heterodimer.

It should be noted that our findings with the ErbB3/ErbBl chimera contradict two previous reports. In chemical crosslinking studies, Tzahar et al. [20] failed to detect NRG-induced dimerization of the ErbB3 extracellular region, but could detect cross-linked dimers when the ErbB3 extracellular region was membrane anchored by a transmembrane domain or lipid anchor. Since ErbB3 was only detected in these studies by affinity labeling with ${ }^{125}$ I labeled NRG, it is not clear whether the observed crosslinked oligomeric species are enhanced by ligand binding, or are constitutive (as suggested in other studies of ErbB3 [16,17]). Alimandi et al. [32] also generated an ErbB3/ ErbB1 chimera with the ErbB3 extracellular region fused to the transmembrane and intracellular domains of ErbB1. This chimera did appear to become phosphorylated following NRG treatment in $32 \mathrm{D}$ cells, by contrast with our findings in $\mathrm{S} 2$ cells [32]. It is unlikely that the different origin of the transmembrane domain in our studies (where it was ErbB3-derived) and those of Alimandi et al. (where it was ErbB1-derived) could explain this discrepancy. The cellular background, therefore, seems a 
315 more likely origin of the difference. Although the murine 32D 316 cell-line used by Alimandi and colleagues has been reported to 317 be ErbB receptor null [11], it may contain endogenous ErbB 318 receptors that are not detectable, but nonetheless interact 319 productively with the exogenous chimera. Indeed, such en320 dogenous receptors could also explain the surprising observation that in $32 \mathrm{D}$ cells (but not BaF3 cells) co-expressed ErbB2 and ErbB3 (or the ErbB3/ErbBl chimera) appear to respond to EGF and betacellulin (despite the fact that neither receptor binds these ligands) [32-35].

Excepting these caveats, we argue that NRG does not induce homodimerization of intact ErbB3 or its isolated extracellular region. Some evidence was previously presented for weak NRG-induced hetero-oligomerization of the ErbB2 and ErbB3 extracellular domains [15] (although others have not seen this [14]), and our data suggest that NRG induces ErbB3/ErbB2 heterodimerization in the absence of ErbB3 homodimerization. Assuming a simple heterodimerization mechanism based on recent structural studies [29], it can be argued that ErbB2 will be activated much more efficiently by ligand-bound ErbB3 than by ligand-bound ErbB4 or ErbB1. Whereas ligand-bound ErbB1 or ErbB4 may prefer to form homodimers than to heterodimerize with, and activate, ErbB2, there is no such homomeric alternative for NRG-bound ErbB3. Given the mitogenic potency of activated ErbB2, this lack of competition from homodimerization may provide part of the reason why the ErbB2/ErbB3 combination appears to be particularly potent in propagating mitogenic signals in tissue culture systems, and has also been identified in a wide array of human tumors $[2,8,12,36]$.

Acknowledgements: This work was supported in part by Grant R01CA096768 from the National Institutes of Health Grants (to M.A.L.) the Jean and Harold Grossman Fellowship (PF-00-174-01-TBE) from the American Cancer Society (to J.M.M.), and fellowship DAMD1798-1-8232 from the US Army Breast Cancer Research Program (to M.B.B.).

\section{References}

[1] Yarden, Y. and Sliwkowski, M.X. (2001) Nat. Rev. Mol. Cell. Biol. 2, 127-137.

[2] Holbro, T. Civenni, G. and Hynes, N.E. (2003) Exp. Cell. Res. 284, 99-110.

[3] Schlessinger, J. (2000) Cell 103, 211-225

(4) Carpenter, G. (2003) Exp. Cell Res. 284, 66-77.

[5] Guy, P.M., Platko, J.V., Cantley, L.C., Cerione, R.A. and Carraway III, K.L. (1994) Proc. Natl. Acad. Sci. USA 91, 8132 8136.

[6] Sierke, S.L., Cheng, K., Kim, H.H. and Koland, J.G. (1997) Biochem. J. 322 (Pt 3), 757-763.
[7] Carraway III, K.L. et al. (1994) J. Biol. Chem. 269, 14303-14306.

[8] Citri, A., Skaria, K.B. and Yarden, Y. (2003) Exp. Cell. Res. 284, $54-65$.

[9] Olayioye, M.A., Neve, R.M., Lane, H.A. and Hynes, N.E. (2000) EMBO J. 19, 3159-3167.

[10] Graus-Porta, D., Beerli, R.R., Daly, J.M. and Hynes, N.E. (1997) EMBO J. 16, 1647-1655.

[11] Pinkas-Kramarski, R., Shelly, M., Glathe, S., Ratzkin, B.J. and Yarden. Y. (1996) J. Biol. Chem. 271, 19029-19032.

[12] Holbro. T., Beerli, R.R., Maurer, F., Koziczak, M., Barbas, C.F.r. and Hynes. N.E. (2003) Proc. Natl. Acad. Sci. USA 100, 8933-8938.

[13] Waterman. H., Alroy, 1., Strano, S., Seger, R. and Yarden, Y. (1999) EMBO J. 18, 3348-3358

[14] Horan, T., Wen, J., Arakawa, T., Liu, N., Brankow, D., Hu, S., Ratzkin. B. and Philo. J.S. (1995) J. Biol. Chem. 270, 24604 24608.

[15] Ferguson. K.M.. Darling, P.J., Mohan. M.J., Macatee. T.L. and Lemmon. M.A. (2000) EMBO J. 19, 4632-4643.

[16] Landgraf. R. and Eisenberg. D. (2000) Biochemistry 39, 85038511.

[17] Cho, H.S. and Leahy, D.J. (2002) Science 297, 1330-1333.

[18] Cho, H.S., Mason. K., Ramyar, K.X.. Stanley, A.M., Gabelli, S.B., Denney Jr., D.W. and Leahy, D.J. (2003) Nature 421, 756760.

[19] Garrett. T.P. et al. (2003) Mol. Cell. 11, 495-505.

[20] Tzahar. E. et al. (1997) EMBO J. 16, 4938-4950.

[21] Greenfield, C.. Patel, G., Clark. S., Jones, N. and Waterfield, M.D. (1988) EMBO J. 7, 139-146.

[22] Guy, P.M., Carraway HI, K.L. and Cerione, R.A. (1992) J. Biol. Chem. 267. 13851-13856.

[23] Gamett. D.C.. Pearson, G., Cerione, R.A. and Friedberg, I. (1997) J. Biol. Chem. 272, 12052-12056.

[24] Lewis, G.D. Lofgren, J.A., McMurtrey, A.E., Nuijens, A., Fendly. B.M., Bauer, K.D. and Sliwkowski, M.X. (1996) Cancer Res. 56, 1457-1465.

[25] Alimandi, M., Romano. A., Curia, M.C., Muraro, R., Fedi. P., Aaronson, S.A., Di Fiore, P.P. and Kralus, M.H. (1995) Oncogene 10. 1813-1821

[26] Wallasch. C., Weiss, F.U., Niederfellner, G., Jallal, B.. Issing, W. and Ullrich. A. (1995) EMBO J. 14, 4267-4275.

[27] Lonardo, F. Di Marco, E. King. C.R., Pierce, J.H., Segatto, O.. Aaronson, S.A. and Di Fiore, P.P. (1990) New Biol. 2, 992-1003.

[28] Huang. G.C., Ouyang. X. and Epstein. R.J. (1998) Biochem. J. $331,113-119$

[29] Burgess, A.W. et al. (2003) Mol. Cell. 12, 541-552.

[30] Plowman. G.D.. Whitney, G.S., Neubauer, M.G., Green, J.M., McDonald. V.L., Todaro. G.J. and Shoyab. M. (1990) Proc. Natl. Acad. Sci. USA $87,4905-4909$.

[31] Kraus, M.H.. Issing. W.. Miki, T., Popescu. N.C. and Aaronson, S.A. (1989) Proc. Natl. Acad. Sci. USA 86, 9193-9197.

[32] Alimandi, M. et al. (1997) EMBO J. 16, 5608-5617.

[33] Pinkas-Kramarski. R. et al. (1998) Oncogene 16, 1249-1258.

[34] Riese II, D.J., Kim, E.D., Elenius, K., Buckley, S., Klagsbrun, M., Plowman, G.D. and Stern, D.F. (1996) J. Biol. Chem. 271, 2004720052.

[35] Riese II, D.J., Bermingham, Y., van Raaij, T.M., Buckley, S., Plowman, G.D. and Stern, D.F. (1996) Oncogene 12, 345-353.

[36] Pinkas-Kramarski. R. et al. (1996) EMBO J. 15, 2452-2467. 


\section{APPENDIX 2 - Chapter IV from PI's doctoral thesis, "Mechanisms of ErbB Receptor}

Oligomerization."

This chapter details the results and interpretations from the analysis of ligand-binding and homodimerization of wild-type and mutant soluble recombinant ErbBl extracellular domains to examine energetic contributions of different regions in the homodimerization surface suggested by recent crystal structures of the receptor extracellular domain. 


\section{CHAPTER IV}

\section{BIOPHYSICAL ANALYSIS OF ERBB1 HOMODIMERIZATION}

\section{SUMMARY}

The four members of the ErbB receptor family are activated through homo- and hetero-interactions driven by ligand-binding to the extracellular domains of the receptors. The extracellular domains are made up of four subdomains, commonly referred to as domains I - IV, and each is thought to play unique roles in activation/dimerization. While these receptors have been studied for more than 20 years, we are only now gaining an appreciation for the molecular events underlying these events. Recent structural studies of the unactivated and homodimeric ErbB1 extracellular domain indicate that this receptor is activated via an unprecedented, receptor-mediated, mechanism. The current model of activation postulates that the extracellular domain shifts between two different conformations - an autoinhibited form which is maintained by intramolecular interactions between domain IV and a loop in domain II, and an extended, active form with the same domain II loop solvent exposed, able to make intermolecular contacts primarily with the equivalent loop of another active receptor molecule. The tethered conformation has a low affinity for growth factors whereas the conformational rearrangements leading to the active form bring the ligand-binding domains I and III in close proximity, resulting in an enhanced affinity for growth factors due to simultaneous 
binding of the two domains by the same ligand molecule. It is therefore postulated that growth factors serve to activate the receptor by stabilizing the extended form, thereby driving the equilibrium between the different conformations towards the active form and increasing its population. In this chapter we discuss a series of experiments testing the effects of various structure-based mutants on both ligand-binding and homodimerization by the ErbB1 extracellular domain. The results of these studies highlight a number of additional contributions to the dimer interface that appear to play a key role in the activation of the receptor, and suggest future studies crucial for the development of better models (based on energetic and structural considerations) of these events. 


\section{INTRODUCTION}

The four members of the ErbB receptor family have a similar domain architecture (see Figure 1-2). All contain an N-terminal extracellular ligand-binding domain composed of four subdomains, typically referred to as domains I - IV (or alternatively L1, C1, L2 and C2), a single? -helical transmembrane domain, and a cytoplasmic effector domain that includes the tyrosine kinase domain and a C-terminal tail capable of recruiting SH2- and PTB-domain containing proteins. The four receptors share significant sequence identity $(40-60 \%)$, but differ markedly in both their ligand binding characteristics and their complement of regulatory tyrosine phosphorylation sites. The growth factor ligands for ErbB receptors can be separated into three distinct classes based on their receptor specificity: the EGF agonists (including EGF itself), which only bind to and activate ErbB1 directly; the neuregulins, which activate only ErbB3 and/or ErbB4

directly, and the bispecific ligands, e.g., betacellulin and heparin-binding EGF, which are capable of activating both ErbB1 and ErbB4 directly. There is no known ligand for ErbB2 alone $(8,15)$.

When inactive, the receptors are believed to be monomers on the cell-surface. Ligand-binding to the receptor extracellular domains (ectodomains) induces homo- and heterodimerization, resulting in autophosphorylation in trans of the regulatory tyrosine residues in their cytoplasmic tails (25). Differential expression of the different ErbB receptors and their ligands allows for combinatorial interactions and fine-tuning of the set of downstream signaling pathways that are activated (1). While the biological outcomes of these signaling pathways have been extensively studied, the mechanistic basis for the 
oligomerization of the receptors is only starting to become well understood at the molecular level.

Given that overexpression or aberrant activation of the ErbB receptors are correlated with a wide variety of human cancers, they are an obvious target for the development of specific, directed chemotherapeutic agents $(22,29)$. This is exemplified by the development of Trastuzumab (Herceptin), a humanized monoclonal anti-ErbB2 antibody used in clinical treatment as a chemotherapeutic agent against ErbB2overexpressing breast cancers. There are now multiple drugs in various stages of clinical trials targeting the ErbB receptors (23). It is clear, however, that a more detailed understanding of how the ErbB receptors become activated will be tremendously useful for the design of future targeted drugs, especially with a view to increase the activity of these agents while minimizing unwanted side-effects. For example, Herceptin use can result in cardiac toxicity (14), and treatment with anti-ErbB1 antibody C225 often result in dermatologic outbreaks (5).

Activation by ligand-induced dimerization is a property of all growth factor RTKs studied to date except those in the insulin receptor family. While the ligand:receptor stoichiometry varies for different receptors, the growth factors are most often found in the receptor-receptor interface, effectively serving to help "stitch" together or cross-link the dimer (25). It had been previously demonstrated that monomeric EGF induces dimerization of a solubilized ErbB1 ectodomain in a 2:2 ligand:receptor complex (19). It was predicted that homodimerization would be mediated by bivalent ligand contacts across the dimer, as was seen for other RTKs, but receptor-mediated homodimerization remained a possibility. A major goal for the field was to obtain detailed models of these 
receptor-receptor and receptor-ligand interactions that could ultimately provide key insights into specific structural elements to be mimicked or inhibited for therapeutic purposes.

Recent structural studies have led to an unprecedented paradigm for ligandinduced ErbB receptor activation (4). However, while crystal structures have provided us with a wealth of information about the mechanisms underlying ligand-binding and receptor dimerization, they are merely "snapshots" of the proteins, providing information only about specific conformations or activation states. Structural differences between the unactivated and dimeric ErbB1 proteins, for example, reveal that ligand-binding and activation induce a complex set of conformational shifts and domain rearrangements (4). In order to gain a more detailed understanding of the contribution from different receptorreceptor contact regions, as well as to make headway into energetic effects of ligandbinding and dimerization, we have generated various structure-based mutants of the soluble ErbBl ectodomain (sErbB1) and have begun to characterize their ligand-binding and dimerization propensities. In particular, we focused on understanding the energetic contribution of parts of the dimer interface other than the dimerization arm itself to receptor activation.

\section{EXPERIMENTAL PROCEDURES}

Growth Factors. Recombinant human epidermal growth factor (EGF) and recombinant human transforming growth factor alpha (TGF?) were purchased from Intergen Corp. (Purchase, NY). Both ligands were purchased lyophilized from PBS, free of carrier proteins and were resuspended in water. 
Cell Culture. Sf9 cells were obtained from Invitrogen Corp. (Carlsbad, CA).

Cells were grown in suspension culture at $27 ? \mathrm{C}$ in SF900-II medium (Invitrogen)

supplemented with penicillin/streptomycin $\left(50 \mathrm{U} \mathrm{ml}^{-1} / 50 ? \mathrm{~g} \mathrm{ml}^{-1}\right)$ (GibcoBRL, Rockville, MD).

sErbB1 Expression Constructs. Generation of the wild-type sErbB 1 expression vector has been previously described (11). Briefly, the coding sequence for residues 1 642 of human ErbB1 (residues $1-618$ of the mature sequence) followed by a hexahistidine tag and stop codon were generated by PCR. A unique Bglll site was introduced upstream of the start codon and a unique XbaI site after the stop codon. The BgllI - Xbal digested PCR product was ligated into BgllI - Xbal digested pFastBacI plasmid. Site-directed mutagenesis was achieved using a standard four-primer PCR method (2) or the QuickChange kit (Stratagene, La Jolla, CA) following the manufacturer's instructions. All PCR-derived products were sequenced by the DNA sequencing facility at the University of Pennsylvania.

Protein Purification. Purification of all sErbB1 variants was performed as previously described (11). Briefly, baculovirus for each construct was generated from pFastBac-constructs in Sf9 cells following instructions in the "Bac-to-Bac" manual (Invitrogen). Sf9 cells were grown in five 1-liter spinner flasks each containing approximately $500 \mathrm{ml}$ culture. High-titer baculovirus stocks were amplified for 4 days before infecting Sf9 cells at approximately $3 \times 10^{6}$ cells/ml density. Infected cells were cultured at $27 ? \mathrm{C}$ for a further 96 hours, then the conditioned media was harvested and clarified by centrifugation. The supernatant was then concentrated approximately 3 -fold and buffer exchanged with 3.5 volumes of $25 \mathrm{mM}$ Tris- $\mathrm{HCl}, 150 \mathrm{mM} \mathrm{NaCl}, \mathrm{pH} 8.0$ 
(Buffer A) by diafiltration using a Millipore Prep/Scale-TFF $30 \mathrm{kDa}$ cartridge. The solution was clarified again by centrifugation and flowed onto a Ni-NTA Superflow column (Qiagen, Valencia, CA). The column was washed with Buffer A, then the protein eluted by washing sequentially with two 1.5-column volumes of Buffer A containing 15, 25, 50,75, 150 and $300 \mathrm{mM}$ imidazole, $\mathrm{pH}$ 8.0. sErbB1-containing fractions were concentrated in Amicon Centriprep YM-50 and Centricon YM-50 centrifugal filter units (Millipore, Billerica, MA) and purified by size exclusion chromatography on a Pharmacia Superose 6 gel filtration column in $25 \mathrm{mM}$ HEPES buffer $\mathrm{pH} 8.0$ containing $150 \mathrm{mM}$ $\mathrm{NaCl}$ (Buffer B). Purified proteins were stored at 4?C.

Surface Plasmon Resonance Studies. EGF and TGF? binding by sErbB1 variants were analyzed by surface plasmon resonance (SPR) experiments on a Biacore 3000 instrument. All experiments were performed in degassed $10 \mathrm{mM}$ HEPES buffer, pH 8.0 containing $150 \mathrm{mM} \mathrm{NaCl}, 3 \mathrm{mM}$ EDTA and $0.005 \%$ Surfactant P-20 at room temperature. EGF and TGF? were immobilized on a Biacore CM5 Biosensor chip by amine coupling as follows: the dextran matrix of three of the four surfaces of the chip was activated with 1-ethyl-3(3-diethylaminopropyl)-carbodiimide hydrochloride (EDC) and N-hydroxysuccinimide (NHS). The growth factors (at $200 ? \mathrm{~g} / \mathrm{ml}$ in $10 \mathrm{mM}$ sodium acetate, $\mathrm{pH} 4.0$ ) were flowed over the activated surfaces at $5 ? \mathrm{l} / \mathrm{min}$ for $10 \mathrm{~min}-\mathrm{EGF}$ over channel 2 and TGF? over channel 3, while channel 1 was left as a reference surface with no ligand treatment. Non-cross-linked ligands were removed and remaining reactive sites were blocked with ethanolamine-HCl. Immobilized EGF contributed a signal of 211.7 RU and TGF? contributed 171 RU. 
Purified sErbB1 proteins at a series of concentrations were flowed over the control, EGF and TGF? surfaces at 5 ?1/min for $10 \mathrm{~min}$ (which was sufficient time for the binding to reach a plateau) and the surfaces were washed with buffer between injections to bring RU values approximately to baseline. Each experiment was performed at least in triplicate. The RU signal corresponding to the height of the plateau was corrected for background effects by subtracting the signal from the protein flowed over the control surface. RU values were plotted against sErbBl concentrations in the Origin software package (OriginLab Corporation, Northampton, MA), and dissociation constants $\left(\mathrm{K}_{\mathrm{D}}\right)$ and maximal binding values for $\mathrm{sErbB1}$ proteins binding to EGF and TGF? surfaces were estimated by fitting plots to a simple binding equation:

$$
\mathrm{R}=\left[\left(\mathrm{R}_{\max } * \mathrm{C}\right) /\left(\mathrm{K}_{\mathrm{D}}+\mathrm{C}\right)\right]+\mathrm{Z}
$$

$\mathrm{R}$ is the measured net $\mathrm{RU}$ at the height of the plateau, $\mathrm{R}_{\max }$ is the calculated maximal binding value for each surface, $\mathrm{C}$ is the concentration of ectodomain and $\mathrm{Z}$ is a simple baseline correction factor.

Analytical ultracentrifugation studies. Ligand-induced dimerization of the $\mathrm{sErbB} 1$ variants was analyzed by sedimentation equilibrium experiments using an XL-A analytical ultracentrifuge (Beckman, Fullerton, CA). Samples of approximately 7.5 ?M wild-type and mutant sErbBl proteins were studied in the presence and absence of a 1.2fold molar excess of EGF. All experiments were performed in Buffer B, which was also used as a reference. Samples were loaded in six-channel charcoal-Epon cells with quartz windows at both ends. Radial scans were performed at 20 ?C at 6000,9000 and 12000 rpm with detection over a wavelength range of $236-285 \mathrm{~nm}$. The partial specific volume of the $\mathrm{sErbB} 1$ proteins was assumed to be $0.71 \mathrm{ml} / \mathrm{g}$ (based on the amino acid 
composition and assumption of approximately $20 \%$ carbohydrate) and the solvent density was assumed to be $1.003 \mathrm{~g} / \mathrm{ml}(11)$. Data were analyzed by fitting to a model of a single, non-ideal species in Origin, which allows one to calculate the weight-averaged molecular mass of the species in the cell. The molecular mass of the samples with EGF added were compared to those without ligand, to determine if binding of growth factor induces homodimerization. The model for a single, non-ideal species is fit with the following formula:

$$
A_{r}=\exp \left[\ln \left(A_{0}\right)+H^{*} M^{*}\left(X^{2}-X_{0}^{2}\right)-B^{*} M^{*}\left(A_{r}-A_{0}\right)\right]+E
$$

$A_{r}$ is the absorbance at radial position $x, A_{0}$ is the absorbance at the reference radius $\left(X_{0}\right)$, $\mathrm{M}$ is the molecular weight, $\mathrm{B}$ is a measure of nonideality and $\mathrm{E}$ is a baseline effect.

$H$ is a constant (based on centrifugation theory) defined as:

$$
\left[\left(1-\operatorname{Vbar}_{\text {protein }} * ? \text { solvent }\right) * ?^{2}\right] / 2 * \mathrm{R} * \mathrm{~T}
$$

Vbar $_{\text {protein }}$ is the partial specific volume of the protein, $?_{\text {solvent }}$ is the density of the solvent, ? is the angular velocity of the rotor, $\mathrm{R}$ is the gas constant and $\mathrm{T}$ is the temperature.

\section{RESULTS}

\section{Development of the model of ligand-induced ErbB1 homodimerization}

Two structures of ligand-bound SErbB1 homodimers were reported in 2002. In one report, the sErbB1 protein was truncated such that most of domain IV was removed, and the bound growth factor was transforming growth factor alpha (TGF?) (13). In the other, the full-length ErbB1 ectodomain bound to epidermal growth factor (EGF) was used, but most of domain IV was disordered. Both structures revealed essentially the 
same overall structural architecture. Unlike structures seen for other growth factor and cytokine receptors, each $\mathrm{sErbB} 1$ molecule binds directly to only one ligand molecule. The receptor homodimerization surface lies on nearly the opposite face from the ligandbinding region, and dimerization is mediated solely by receptor-receptor contacts. The dimerization interface is dominated by a long loop in domain II of one molecule making contacts to the corresponding loop of the other molecule in the dimer, and vice versa. Interestingly, this so-called "dimerization arm" is precisely the same loop that forms the intramolecular tether in ErbB3 (6). The sErbB1 homodimer is shown in Figures 4-1 and 4-4.

The current model of ligand-induced sErbBl homodimerization was fully realized after the structure of the unactivated ErbB1 ectodomain was solved (10) (Figure 4-1). This structure revealed that in the quiescent state (reached by low $\mathrm{pH}$ in this case), the ErbB 1 ectodomain adopts a conformation similar to that seen in the structure of s-ErbB3, i.e., the receptor is held in a tethered conformation maintained by interactions between the dimerization arm loop of domain II and residues near the C-terminus of domain IV. In addition, the bound EGF in the unactivated receptor makes contacts only to domain I of the receptor, whereas the homodimer structures reveal the ligands bound to both domains I and III. In order to model the transition from the tethered state to the conformations seen in the dimer structures, domains I and II (treated as a single, rigid body) must undergo a large rotation and translation about an axis defined by the boundary between domains II and III (10). These conformational changes serve two purposes - to "break" the intramolecular tether, exposing the dimerization arm, and to dock the bound EGF into the same sites as in the dimer. 


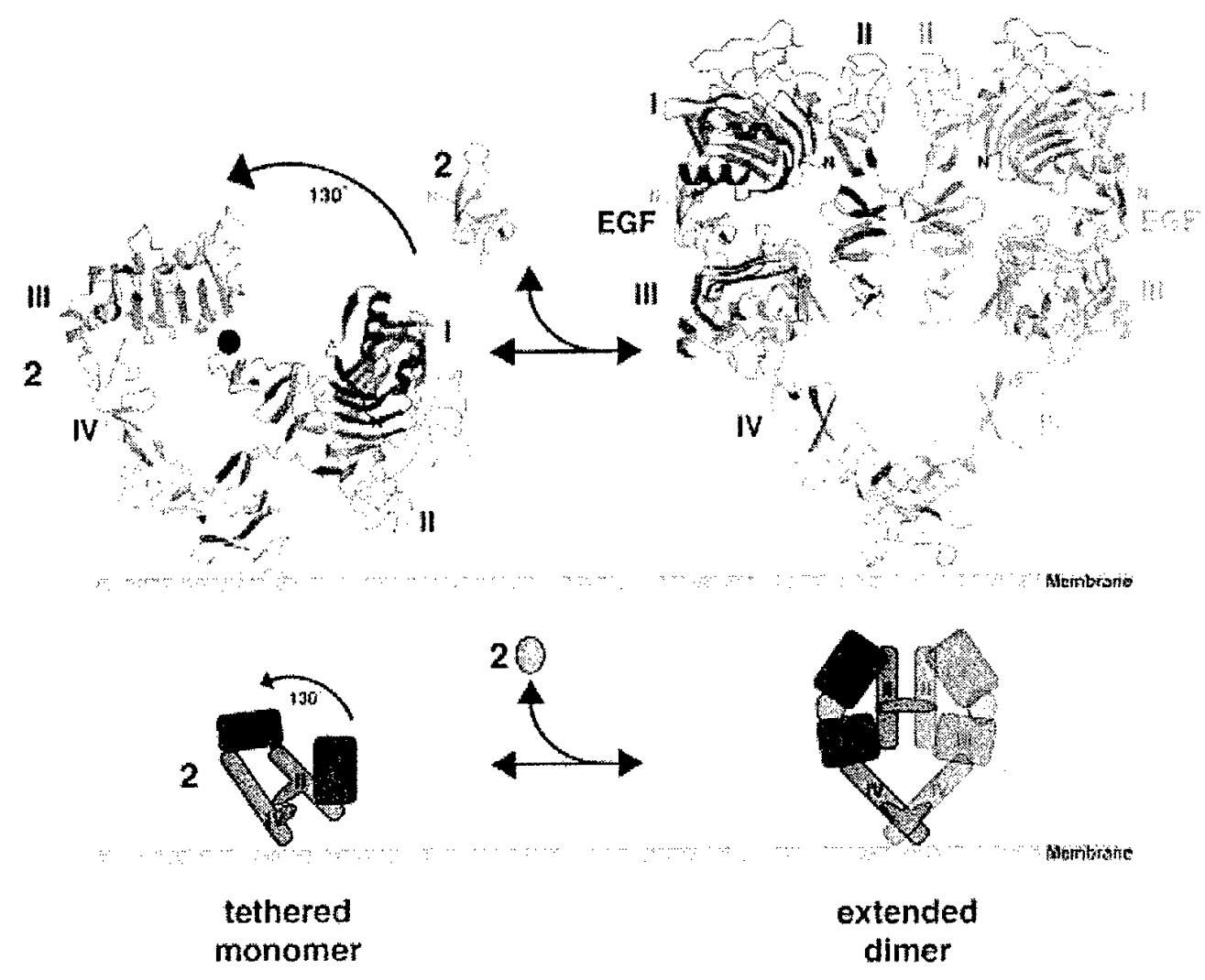

FIGURE 4-1

\section{Model of ligand-induced ErbB1 homodimerization}

This figure depicts the structural rearrangements involved in the transition from the tethered, autoinhibited conformation (left) to the extended form stabilized by ligandbinding and homodimerization (right). The top panel presents the structures in ribbon diagrams and the bottom in cartoon format. The structure of domain IV in the dimeric conformation is not known, but was modeled into the figure based on the structure of the autoinhibited molecule (10). The gray bar identifies the proposed position of the plasma membrane. Disruption of the intramolecular tether extends the molecule, bringing domains I and III in close proximity to allow for high affinity binding of EGF. Extension of the ectodomain also exposes the domain II dimerization arm to solvent, allowing for intermolecular interactions with the equivalent loop of another molecule to stabilize the homodimer. Figure adapted from (4). 
We generated a model for the activation of ErbB1 by its ligands as follows: The protein exists in an equilibrium between the tethered and extended conformations seen in the crystal structures. In the absence of ligand, the intramolecular tether dominates and the ectodomain is largely maintained in the autoinhibited conformation, unable to make the necessary receptor-receptor contacts through the dimerization arm to stabilize a homodimer. In such a conformation, domains I and III are too far apart for growth factors to be able to bind both domains simultaneously. The affinity for ligand is therefore low. In the extended conformation, these domains are brought closer together, so ligand molecules will be able to contact both surfaces and thus bind with higher affinities. Ligand-binding to the extended form should stabilize the dimerizationcompetent conformation and therefore drive the equilibrium towards homodimerization and activation of the receptors (a schematic of this model is presented in Figure 4-1).

In order to test this model, and to obtain an estimate of the tether strength, we generated a series of mutants based on the structure to disrupt the intramolecular tether. Namely, we mutated all of the polar/charged residues in domain IV seen to be involved in hydrogen bonding to the dimerization arm to alanine (D563A/H566A/ K585A) in order to disrupt these interactions. We predicted that these mutations would shift the equilibrium between the tethered and extended conformations towards the extended form, resulting in an increase in the measured affinity for EGF. As shown in Figure 4-2, surface plasmon resonance measurements of EGF-binding by these mutants (using the Biacore instrument) revealed that disruption of the tether indeed increased affinity for EGF about 3-fold, from approximately $130 \mathrm{nM}$ (for the wild-type protein) to approximately $50 \mathrm{nM}$ (for the mutant containing all three mutations - dubbed the "triple 


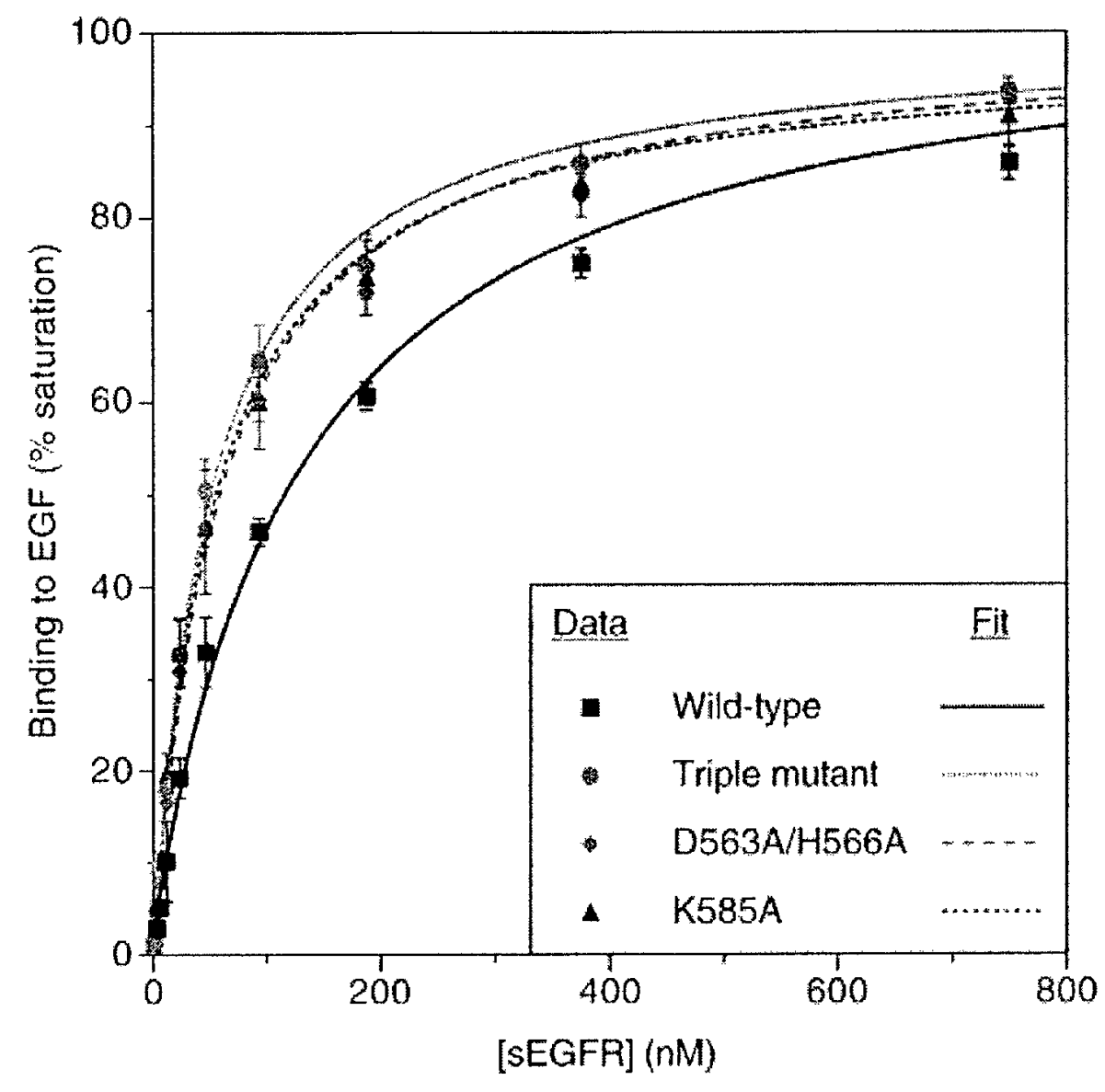

FIGURE 4-2

\section{Affinity for EGF is enhanced through mutagenic disruption of intramolecular domain II - IV interactions}

Variants of the soluble ErbBl ectodomain were generated containing mutations of $\mathrm{K} 585 \mathrm{~A}, \mathrm{D} 563 \mathrm{~A} / \mathrm{H} 566 \mathrm{~A}$, or all three simultaneously (triple mutant). The binding affinity for EGF was measured for each of these mutants, along with the wild-type protein, using surface plasmon resonance experiments on a Biacore instrument. Affinities were enhanced up to approximately 3 -fold by the mutations, with wild-type protein binding with a $\mathrm{K}_{\mathrm{D}}$ of approximately $130 \mathrm{nM}$ and the triple mutant gave a $\mathrm{K}_{\mathrm{D}}$ of approximately 51 nM. Figure reproduced from (10). 
mutant") (10). This is similar to the increase in ligand-binding seen when domain IV was deleted in its entirety (9).

\section{Structure-based mutants of the homodimer interface}

The model of ligand-induced ErbB1 activation shown in Figure 4-1 provides a description of the gross conformational changes that occur during the stabilization of the receptor ectodomain in the homodimeric conformation. However, the simple rotational and translational movements are not sufficient to fully describe the process. Indeed, that ligand-binding does more than simply extend the protein to expose the dimerization arm is shown by the fact that a truncated form of sErbB1 that lacks domain IV still requires EGF-binding in order to dimerize $(9,13)$. Moreover, EGF is required for our tethermutant to dimerize in vitro (not shown), and the tether mutations do not promote constitutive activation in the context of the full-length receptor in living cells. As shown in Figure 4-3, which overlays domain II structures from the monomeric (red) and dimeric (green and cyan) structures, there are additional conformational alterations spread over multiple regions in domain II when ligand binds and promotes dimerization (10).

Finally, a number of inter-receptor contact points outside those in the dimerization arm were seen or inferred $(10,13)$, as shown in Figure 4-4. We therefore generated sErbB1 mutants with alterations at these positions, to investigate the roles of these interaction sites in $\mathrm{SErbB1}$ dimerization.

Two of the mutants generated were described in the structural studies of the ErbB1 homodimer, and were found experimentally in previous reports to disrupt EGFinduced ErbB1 homodimerization and activation. One mutant, described by Ogiso, et al. 


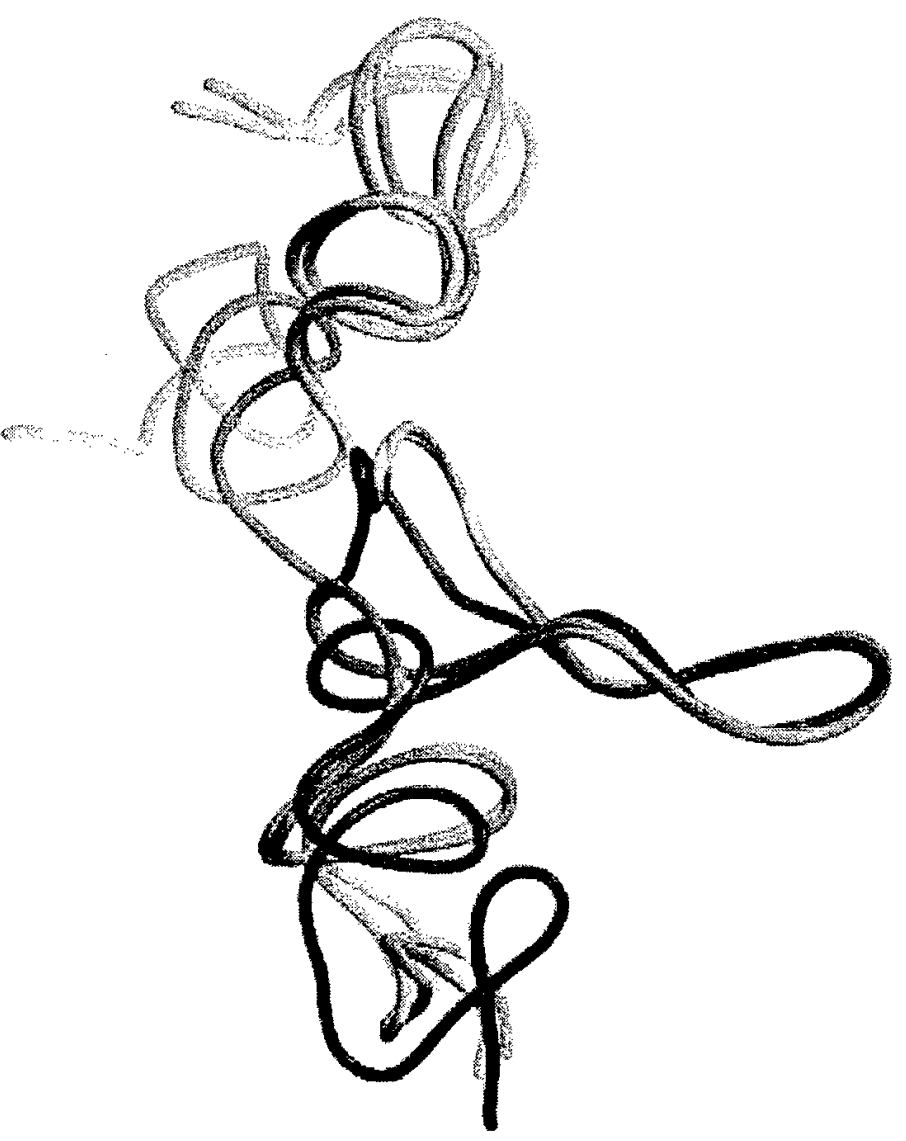

FIGURE 4-3

Ligand-induced homodimerization results in conformational changes in domain II

Domain II from the three structures of the ErbBl ectodomain are presented in worm representation. The trace in green is derived from the structure of the full-length protein in complex with EGF (24), the blue trace from the truncated ectodomain bound to TGF? (13) and the red trace from the autoinhibited, intramolecularly tethered protein (10). The dimerization arms from each structure are aligned as a point of reference. 


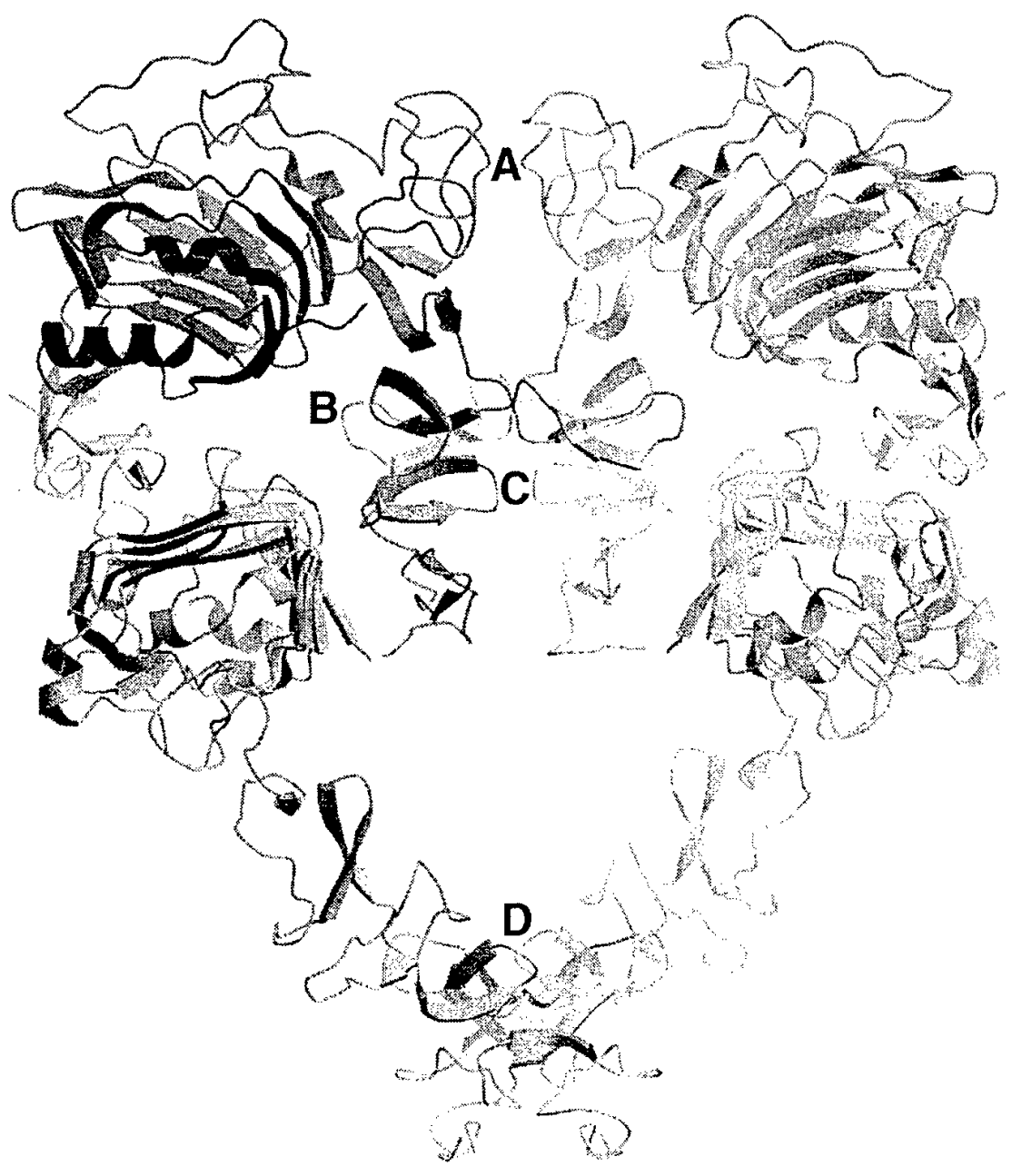

FIGURE 4-4

\section{Regions mutated in the ErbB1 ectodomain}

The predicted full-length ErbB1 ectodomain homodimer is presented in ribbon diagram. The general regions mutated in this study are identified as follows: position $\mathbf{A}$ is Gln ${ }^{194}$, which we mutated to Ala. B highlights the domain II "dimerization arm" mutated in Y251A/R285S and the domain Il hexa-mutant. $C$ is the loop containing $\mathrm{Asp}^{279}$ and $\mathrm{His}^{280}$, both of which were mutated to Ala simultaneously. D contains the $\mathrm{Cl}_{\mathrm{Nd}}$ loop, a second putative dimerization arm that we deleted in its entirety. Figure adapted from (4). 
(24), has a single point mutation in the dimerization arm (Y251A) as well as a point mutation near the C-terminal end of domain II (R285S), both of which contribute to removing four inter-receptor hydrogen bonds involved in stabilizing the homodimer. We unfortunately do not have reliable data on this mutant as we were unable to purify the protein in sufficiently for accurate biophysical measurements. The other variant, described by Garrett and colleagues (13), has 6 point mutations in the dimerization arm as follows: Y246D, N247A, T249D, Y251E, Q252A and M253D (herein referred to as the domain II hexa-mutant). It should be noted that our protein has $\mathrm{Tyr}^{246}$ mutated to Glu rather than Asp. The regions mutated in these proteins are indicated as region " $B$ " in Figure 4-4.

Three other mutants were generated based on other regions seen in the structures to contribute to the dimer interface. Two of these mutants were based on contacts sites identified by Garrett, et al., consisting of residues that participate in hydrogen bond formation between the two molecules of the receptor homodimer (13). We generated one protein with a single point mutation at the $\mathrm{N}$-terminus of domain II (Q194A) (Figure 4-4 A) and another with a pair of mutations in domain II C-terminal to the dimerization arm (D279A/H280A) (Figure 4-4 C) in order to disrupt these salt bridges. The other mutant contains a deletion in domain IV and is based on the model of the full-length ErbBI ectodomain homodimer generated by Ferguson and colleagues (10). Neither of the structures of the activated receptor provides detail about domain IV, as the domain was disordered in the structure of the full-length protein (24), and most of the domain was deleted in protein crystallized for the other structure (13). However, a model of the homodimer with domain IV (derived from the autoinhibited structure) added indicates 
that a loop of 10 residues (from $\mathrm{Val}^{575}$ through $\mathrm{Trp}^{584}$ ) may also make contacts across the dimer (10). In addition, peptide mimetics of the C-terminal portion of domain IV have been demonstrated to block ErbB receptor dimerization (3), and recent unpublished work reveals that the structure of domain IV in full-length $\mathrm{sErbB1}$ does, in fact, resemble the model depicted in Figures 4-1 and 4-4 (4). We deleted this loop to look for effects mediated by this second putative dimerization arm (this protein will be referred to as the "? $\mathrm{Cl}_{\mathrm{rVd}}$ " mutant, based on the nomenclature in (10)) (Figure 4-4 D).

\section{Ligand-binding studies of the sErbB1 mutants}

The model of ligand-induced homodimerization postulates that the extended, dimerization-competent conformation of the ectodomain will have a higher affinity for growth factors than the tethered, autoinhibited conformation. We therefore predicted that disruption of any region involved in stabilizing the homodimer would translate into a reduction in ligand-binding affinity. We purified recombinant wild-type and mutant sErbB 1 proteins, then measured their affinity (by surface plasmon resonance) for both EGF and TGF? immobilized on Biacore CM5 chips.

Various concentrations of ectodomains (ranging from approximately 6 ? M to 6 nM) were flowed over the growth factor and control surfaces, resulting in a series of "sensorgrams" for each receptor binding to each ligand. Representative data for each protein binding to EGF and TGF? are presented in Figure 4-5. Binding curves for the various proteins were generated (Figure 4-6) and affinities for both EGF and TGF? were calculated using a simple binding equation (presented in Table 4-1).

The measurements of binding affinity by the wild-type protein served as an 

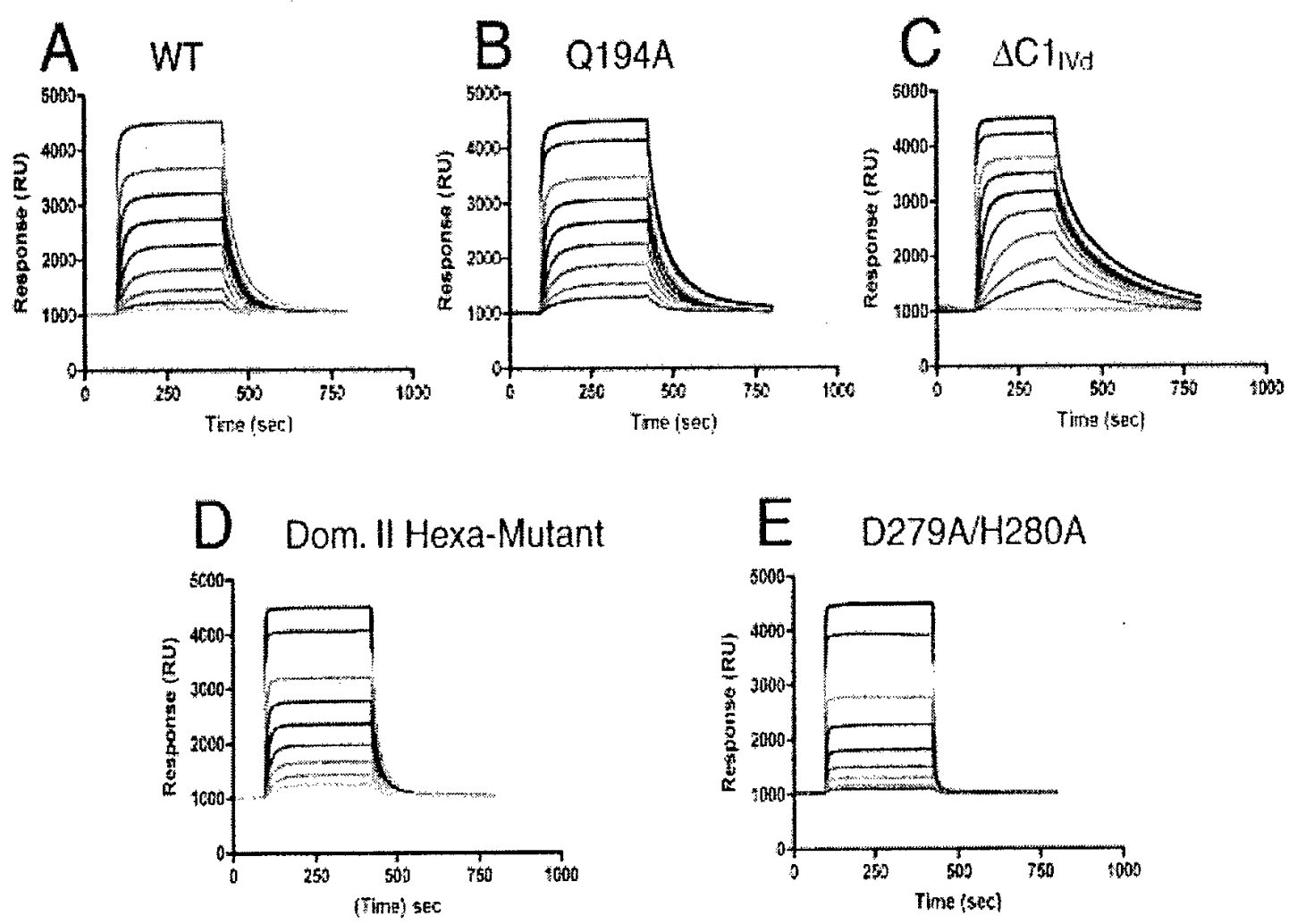

FIGURE 4-5

\section{Surface plasmon resonance analysis of ligand-binding by mutants}

EGF and TGF? binding by wild-type and mutant $\mathrm{sErbB} 1$ proteins were measured by SPR experiments on a Biacore 3000 instrument as described in "Experimental Procedures." Representative sensorgrams are presented for each protein binding to the EGF surface as follows: (A) wild-type, (B) Q194A, (C) ? C1 IVd, (D) domain II hexamutant and (E) D279A/H280A. The concentration of sErbB1 flowed over the surface is depicted by color, as follows: Black: $6000 \mathrm{nM}$, red: 3000 ? M, yellow: $1500 \mathrm{nM}$, orange: $750 \mathrm{nM}$, green: $375 \mathrm{nM}$, blue: $187.5 \mathrm{nM}$, purple: $93.75 \mathrm{nM}$, cyan: $46.88 \mathrm{nM}$, brown: $23.44 \mathrm{nM}$, lime: $11.72 \mathrm{nM}$ and pink: $5.86 \mathrm{nM}$. 

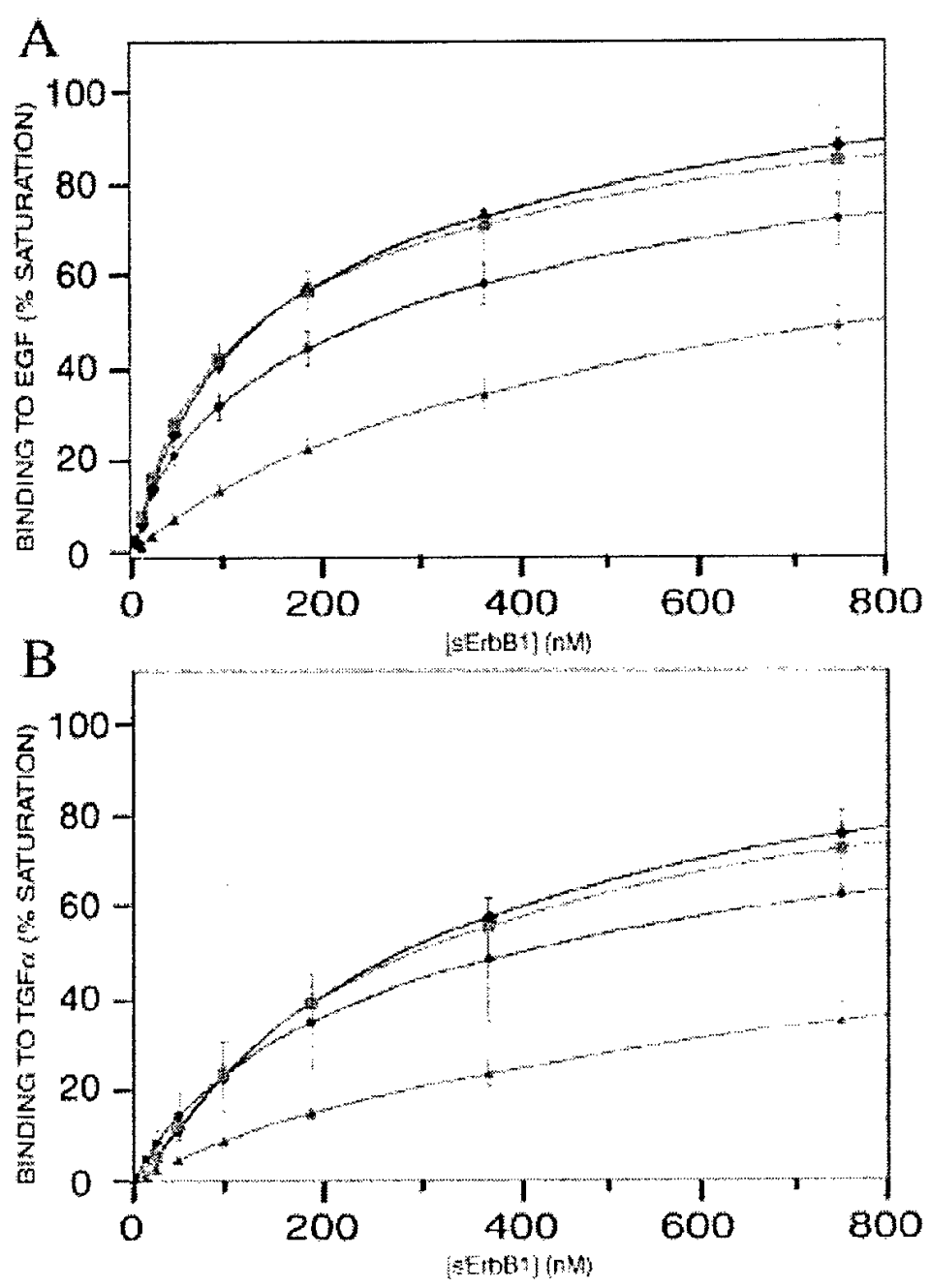

FIGURE 4-6

\section{Binding curves for immobilized EGF and TGF?}

SPR measurements of wild-type and mutant sErbB1 proteins binding to EGF (A) and TGF? (B) immobilized on Biacore CM5 chips were analyzed to generate binding curves as described in "Experimental Procedures." Data presented represent mean values for each concentration (from at least three independent experiments) and error bars are standard deviations. The curves are color-coded for identification of the sErbB1 variants as follows: yellow: ? $\mathrm{C} 1_{\mathrm{rd}}$, black: wild-type, red: Q194A, blue: domain II hexa-mutant, green: D279A/H280A. 
EGF

TGF?

(nM)

(nM)

\begin{tabular}{|c|c|c|}
\hline Wild-Type & $175+/-6$ & $356+/-17$ \\
\hline Q194A & $162+/-5$ & $306+/-20$ \\
\hline Dom. II Hexa-Mutant & $270+/-14$ & $357+/-53$ \\
\hline D279A/H280A & $603+/-22$ & $871+/-62$ \\
\hline C1 $_{1 \text { 1Vd }}$ & $77+/-12$ & $109+/-7$ \\
\hline
\end{tabular}

TABLE 4-1

\section{Calculated affinities for EGF and TGF?}

$K_{D}$ values for growth factor-binding by wild-type and mutant ErbB1 ectodomains were calculated based on SPR experiments. Means from at least three independent experiments are presented (in units of nanomolar (nM)) along with standard deviations. 
internal control and were found to be consistent with previous studies from our lab $(10,11)$ (and unpublished data). We find no difference in TGF? binding by the domain II hexa-mutant, and only a weak reduction in affinity for EGF. This data is in contrast to published results demonstrating a 15-fold reduction in affinity for EGF by the same set of mutations, albeit in the context of a truncated protein lacking most of domain IV (13). The Q194A mutation also seems to have no great effect on binding either growth factor, although statistically our measurements indicate a slight enhancement of ligand-binding. In contrast, the $\mathrm{D} 279 \mathrm{~A} / \mathrm{H} 280 \mathrm{~A}$ and $? \mathrm{C}_{\mathrm{IVd}}$ mutants demonstrate more striking ligandbinding affinities. The D279A/H280A mutant binds both EGF and TGF? about 3-fold more weakly than the wild-type protein, whereas the $? \mathrm{C} 1_{\mathrm{Nd}}$ mutant has an approximately 3-fold stronger affinity for ligands.

SPR experiments not only allow for calculation of equilibrium binding constants, but also provide information on the kinetics of the interactions between the ectodomains and the ligands (27). Again, we find that the Q194A mutant (Figure 4-5 B) appears to behave similarly to the wild-type protein (Figure 4-5 A), whereas the other mutants all demonstrate altered kinetics. The ? $\mathrm{Cl}_{\mathrm{NVd}}$ (Figure 4-5 C), domain II hexa-mutant (Figure 4-5 D) and the D279A/H280A (Figure 4-5 E) mutants all have increased association rates with the ligands, as revealed by the reduced time required to reach the equilibrium plateau. In contrast, the domain II hexa-mutant and the D279A/H280A mutants both demonstrate more rapid dissociation rates, whereas the $? \mathrm{C} 1_{\mathrm{IVd}}$ mutant has a slower off rate. The implications of these altered kinetics are considered in the "Discussion" section.

\section{sErbB1 homodimerization}


We predicted that some of the mutations in structurally-identified homodimerization interfaces should destabilize ligand-induced receptor dimers. We therefore assessed the ability of the wild-type and mutant sErbB1 proteins to homodimerize in the presence of EGF using sedimentation equilibrium (SE) experiments in an analytical ultracentrifuge. We analyzed each ectodomain variant in the presence and absence of EGF as described in "Experimental Procedures." Analytical ultracentrifugation data are presented for each protein in the presence and absence of 1.2fold molar excess EGF (Figure 4-7) and is summarized in Table 4-2. The data in Figure 4-7 are presented as plots of the natural logarithm of the absorbance at $278 \mathrm{~nm}$ (a measure of protein concentration) versus one-half the difference of the square of the radial position $\left(r^{2}\right)$ and the square of the distance to the meniscus $\left(r_{o}{ }^{2}\right)$ from experiments performed at centrifugal speeds of $9000 \mathrm{rpm}$. The slopes of these lines are proportional to weight-averaged molecular mass, and can therefore serve to indicate whether homodimerization occurs.

We found that the wild-type, Q194A and ? $\mathrm{C} 1_{\mathrm{IVd}}$ proteins all homodimerize similarly. As presented in the literature, the domain II hexa-mutant fails to increase in size in the presence of ligand, demonstrating that this mutant does indeed remain monomeric, even when bound to growth factor. Finally, the D279A/H280A mutant appears to homodimerize weakly in the presence of EGF. We have therefore generated a set of mutants that not only demonstrates a range of ligand-binding affinities, but also in the ability to undergo growth-factor-induced homodimerization. By fitting to a simple dimerization model, we are able to calculate relative $\mathrm{K}_{\mathrm{D}} \mathrm{S}$ of homodimerization (presented 

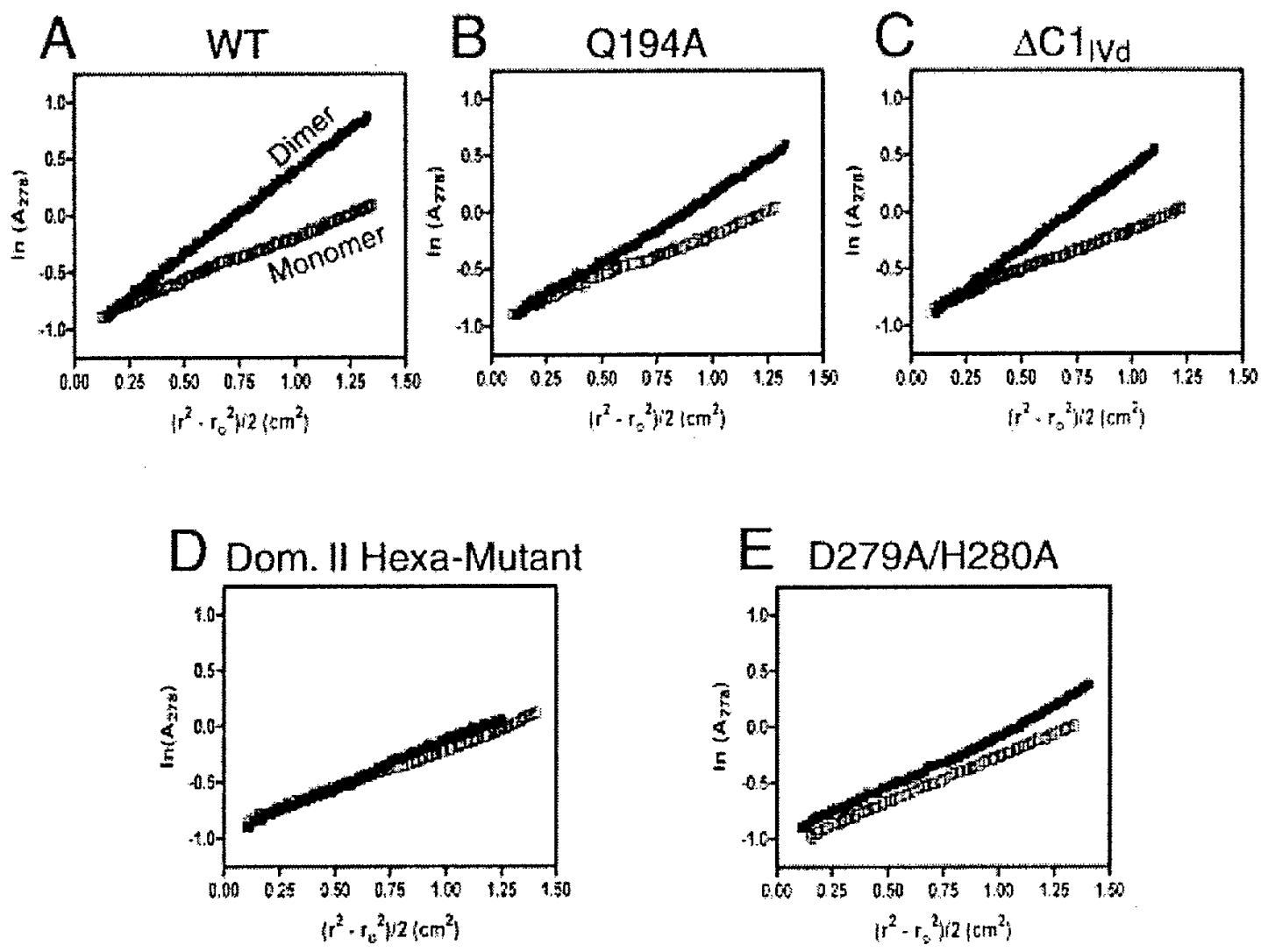

FIGURE 4-7

\section{Analysis of oligomeric state of sErbB1 derivatives by sedimentation equilibrium experiments}

The ability to homodimerize upon ligand-binding was examined by sedimentation equilibrium. Experiments were performed on approximately 7.5 ? $\mathrm{M}$ protein both in the presence (filled squares) and absence of EGF (open squares). The slope of each line is proportional to the molecular mass of the complex, as discussed in the text. Wild-type (A), Q194A (B) and ? $1_{\mathrm{rVd}}(\mathbf{C})$ all demonstrate complete ligand-induced homodimerization. The domain II hexa-mutant (D) remains completely monomeric even when bound to EGF, and the D279A/H280A mutant (E) homodimerizes only weakly. 


\begin{tabular}{|c|c|c|}
\hline \multicolumn{2}{|c}{ HOMODIMERIZATION } & K $(? \mathrm{M})$ \\
\hline Wild-Type & COMPLETE & 2.7 \\
\hline Q194A & COMPLETE & 2.9 \\
\hline ? C1 ${ }_{1 V d}$ & COMPLETE & 2.3 \\
\hline Dom. II Hexa-Mutant & ABSENT & Not Calculated \\
\hline D279A/H280A & VERY WEAK & 13.7 \\
\hline
\end{tabular}

TABLE 4-2

\section{Summary of data from sedimentation equilibrium experiments}

Data presented in Figure 4-6 was analyzed to determine the oligomeric state of each sErbB1 variant with and without added EGF as well as the $\mathrm{K}_{\mathrm{D}}$ for dimerization. The wild-type, Q194A and ? $\mathrm{Cl}_{\mathrm{IVd}}$ all demonstrated full ligand-induced homodimerization with similar dissociation constants. The D279A/H280A mutant displays an intermediate phenotype with a drastically reduced ability to homodimerize in response to ligandbinding, whereas the domain II hexa-mutant remains completely monomeric, even in the presence of excess growth factor. 
in Table 4-2). wild-type: 2.7 ? M, Q194A: 2.9 ? M, D279A/H280A: 13.7 ? M, C1 IVd $_{\mathrm{Vd}}: 2.3$

?M. We could not fit the data for the domain II hexa-mutant as it does not dimerize.

\section{DISCUSSION}

Our understanding of the mechanisms of activation of the ErbB receptor family changed dramatically in the last few years due to the plethora of structural studies published recently. These studies reveal an unprecedented mode of ligand-induced receptor-mediated dimerization and suggest a compelling model for the activation of the ErbB1 RTK. However, it is clear that there are still numerous details missing from the model, largely due to the fact that the crystal structures present static views of the proteins.

We have generated a number of mutants of the soluble ErbB1 ectodomain based on the homodimerization interfaces identified in the structural studies. We have characterized the ligand-binding of these proteins as well as their ability to undergo growth factor-induced homodimerization as a first step towards generating a more complete model of receptor activation. For simplicity, the mutants will be discussed in order of their location in the protein, starting at the N-terminus.

The Q194A mutant exhibits little or no change in ligand-binding affinity and dimerizes normally in the presence of EGF, indicating that this region likely contributes little (if at all) to stabilization of the homodimer. Indeed, as it is reported that the total buried surface area of the entire region encompassing residues 193-195 and 204-205 is only $225 \AA^{2}(13)$, it is not surprising that this mutation caused little change in dimerization. The hydrogen bonding interactions between $\operatorname{Gln}^{194}$ of the two ErbB1 
ectodomains were only seen in the Garrett, et al. structure, but not in that of Ogiso and colleagues. It should be noted that our data indicate a very weak, although statistically significant, increase in affinity for both ligands, but equivalent dissociation constant for homodimerization (see Tables 4-1 and 4-2).

The domain II hexa-mutant was previously reported to remain monomeric in the presence of EGF and to bind the growth factor with an approximately 15 -fold reduced affinity (13). The data from our SE experiments corroborate the findings on the oligomeric state, i.e., we also see no homodimerization of this mutant when EGF is added. However, our SPR studies indicate that these mutations cause little or no effect on the equilibrium binding constant. Indeed, the $K_{D}$ value for TGF? -binding for both proteins is indistinguishable, and we only see a mild reduction in affinity for the domain II hexa-mutant for EGF as compared to the wild-type protein.

Interpretation of the domain II hexa-mutant data is complicated by the fact that the mutation made will almost certainly disrupt formation of the intramolecular tether as well as receptor-receptor interactions in the dimer. Yet, the ligand-binding affinity is slightly reduced (rather than being increased by 3 - fold, as expected for a tether mutant). It seems reasonable to argue that the 4-6 fold difference in binding affinities of the domain II hexa-mutant and other tether mutants reflects the energetic contribution of dimerization to ligand-binding. Indeed, dimerization will restrict the relative position of domains I and III, and thus modulate EGF-binding affinities (and vice versa). As the domain II hexa-mutant binds growth factors with similar affinity to wild-type protein, we assume that this protein adopts the extended conformation upon ligand-binding (or its affinity is greater than that of domain III alone). This model therefore implies that the 
ligand-stabilized transition from the tethered, autoinhibited conformation to the extended form occurs irrespective of the dimerization state of the receptor. This mutant then appears to provide the first known measurement of the affinity for full-length monomeric sErbB1 to EGF (and TGF?) as all previous studies have been performed with full-length, wild-type (dimerization competent) protein or with truncated variants. This should prove to be very useful to the field, especially for developing sophisticated mathematical models of receptor signaling in cells.

Our data argue that the processes of ligand-binding and homodimerization are energetically coupled. The kinetics of binding exhibited by the domain II hexa-mutant also support this scenario, as the rapid association rate for ligand indicates that this protein, like the triple mutant, is primed to bind ligand, i.e., that the intramolecular tether is likely to be constitutively weakened. The very rapid off rate is consistent with the failure of this protein to dimerize.

We are unable to comment on the effects of the Y251A/R285S mutant, due to insufficient quantities of purified protein with which to perform our studies. Preliminary test expression studies of this protein revealed that it should be expressed at similar, if not higher, levels than other mutants. In addition, Ogiso and colleagues were able to successfully express the full-length ErbBl receptor containing these same mutations, indicating that they do not result in drastic destabilization of the protein (24). It is therefore expected that our results were due to poor purification conditions and not inherent problems with the mutant. It would be of great interest to compare the biophysical characteristics of this mutant with the domain II hexa-mutant as both are reported to inhibit homodimerization, even though the set of mutations is largely distinct. 
This is especially important given that the mutant described by Ogiso and colleagues has $\mathrm{Tyr}^{246}$ intact, so it may maintain the intramolecular tether more tightly than the domain II hexa-mutant, which could help resolve our interpretation of the data. Comparison of the Y251A/R285S mutant with the domain II hexa-mutant would therefore help parse out the effects of dimerization from those involved in disruption of the intramolecular tether on stabilization of ligand-binding.

The results from the $\mathrm{D} 279 \mathrm{~A} / \mathrm{H} 280 \mathrm{~A}$ mutant are interesting. The Biacore studies on this protein revealed significant reductions in affinity for both EGF and TGF? (approximately 2.5 - 3.5-fold), generating affinities similar to those measured for ligandbinding by domain III alone (19). This would be consistent with the idea that mutating these two residues results in a reduced ability to productively bring domain I close enough to domain III to allow bound growth factors to make contacts to both domains simultaneously. Ligand would then be expected to bind only domain III. The kinetics of the interaction between the mutant and ligands are also interesting. While the equilibrium binding of this mutated protein to growth factors is weaker than that of the wild-type ectodomain, the mutant actually appears to associate and dissociate from ligand more rapidly. SE experiments indicate that this protein, when bound to EGF, homodimerizes only very weakly. We propose, therefore, that the D279A/H280A mutations interfere with the normal conformational changes (likely those in domain II) that occur upon the rearrangement from the tethered to the extended conformation. It is likely that these mutations restrict the number of conformationals available to the protein, but at least one of them is suitable for binding ligand, resulting in an increased "on" rate. However, as this mode of binding must not be the same conformation associated with 
stabilization of the homodimer, the protein does not gain the enhancement in ligandbinding from dimerization-induced stabilization, resulting in the rapid "off" rate also detected.

Recent studies with anti-ErbB1 antibodies also support our interpretation of the data on the D279A/H280A mutant. Monoclonal antibody (mAb) 806 was raised against a truncated mutant of ErbB 1 lacking the $\mathrm{N}$-terminal 267 residues (known as de2-7 or EGFRvIII) and has been demonstrated to bind readily to cells expressing the de2-7 mutant or the recombinant mutant ectodomain in solution. However, it only binds cells expressing wild-type ErbB 1 when overexpressed and to wild-type sErbB 1 when denatured or immobilized on solid surfaces. $(16,18,21)$. This indicates that the epitope for the antibody exists in both the de2-7 and wild-type receptors, but is likely to be conformationally sensitive. The epitope is now known to occur in a region very close to $\mathrm{His}^{280}$ (A. W. Burgess, personal communication). The data from our D279A/H280A mutant combined with the mAb 806 studies indicate that interactions in this region of domain II are critical for conformational changes that occur upon ligandbinding/stabilization of the extended conformation and dimerization. As discussed earlier in this chapter, comparisons of the unactivated and dimeric structures of sErbB1 revealed numerous such changes (Figure 4-3). Further studies are necessary to determine the precise contribution of this region to the overall process of ligand-induced receptor activation.

The $\mathrm{Cl}_{\mathrm{Nd}}$ deletion results in an increase of affinity for growth factors similar to that seen with the domain IV triple mutant. This effect was unexpected as the two sets of mutations were actually designed to generate opposite outcomes - the ? $\mathrm{C}_{\mathrm{IVd}_{\mathrm{d}}}$ mutant was 
predicted to have a deletion of a putative second dimerization arm which should therefore destabilize the extended, dimerization-competent conformation, resulting in a decreased affinity for growth factors. The mutations in the triple mutant were targeted to relieve autoinhibition and drive the equilibrium towards the higher affinity, extended conformation. SE experiments also indicate that the $? \mathrm{C}_{1 \mathrm{Vd}}$ mutant homodimerizes as efficiently as the wild-type protein (Table 4-2). Our results therefore indicate that deletion of the $\mathrm{Cl}_{\mathrm{IVd}}$ loop result in a similar disruption of the intramolecular tether as the triple mutant, thereby driving the population towards the higher-affinity state. The ligand-interaction kinetics also support this notion, as the protein seems to associate more rapidly with growth factors than the wild-type protein, yet has a much slower dissociation rate, consistent with efficient homodimerization. We suggest that these results reflect disruption of the intramolecular tether (which removes an energetic barrier to extension into the ligand-binding conformation(s), increasing the "on" rate) and the retention of this mutant's ability to homodimerize (which stabilizes the extended, ligand-bound form, thereby decreasing the "off" rate of the ligand). We do not yet know the precise mechanism by which deletion of the $\mathrm{C} 1_{\mathrm{IVd}}$ loop results in these responses. Given that the $\mathrm{C} 1_{\text {IVd }}$ loop abuts the dimerization arm in the tethered conformation, it is likely that this loop helps to stabilize the intramolecular interactions, and thus its deletion is likely to weaken the autoinhibited state and drive the protein towards the extended conformation. Alternatively, deletion of this loop might simply disrupt the local structure of this region of domain IV, resulting in a misalignment of the residues and side-chains that normally interact with the domain II loop to complete the tether. Importantly, by contrast with the suggestion made by Schlessinger (26), as well as our own model, the $\mathrm{C} 1_{\mathrm{rVd}}$ loop does not 
appear to contribute significantly to the thermodynamics of receptor dimerization, despite being related closely in structure to the dimerization loop in domain II. It is interesting that in spite of this finding, Greene and colleagues (3) report that a peptide based on this region can inhibit NRG-induced sErbB1-sErbB3 heterodimerization and as well as the biological activity of full-length ErbB1 in cells stimulated with EGF.

The determination of the boundaries for the deletion in the $\mathrm{C} 1_{\mathrm{rVd}}$ mutant were derived by aligning the sequence of wild-type $\mathrm{sErbB1}$ with the extracellular domain of the Drosophila EGF receptor (DER) (20). As can be seen in Figure 4-8, this entire set of residues is missing from domain IV of the insect protein. Interestingly, unlike the mammalian protein, DER contains five extracellular subdomains. If the $\mathrm{Cl}_{\mathrm{Nd}}$ loop is involved in maintaining the intramolecular tether in the mammalian receptor, this would indicate that the Drosophila protein does not behave in the same fashion. It is currently unclear what purpose the fifth subdomain in DER serves, but it is tempting to propose that this domain might function to stabilize an autoinhibited, intramolecularly tethered conformation in lieu of that seen in the mammalian system.

The results presented here allow us to more accurately describe the energetic contributions of various regions in the ErbBl ectodomain to ligand-induced homodimerization. We are currently in the process of refining these data, as well as examining other mutants. Future studies employing other techniques will also provide key information about the thermodynamics of ligand-binding and dimerization.

One concern that arises from the crystallographic studies is the possibility that the tethered form of the receptor is simply an artifact of crystallization. The fact that a very similar configuration is seen for ErbB3 (6) as well as ErbB1 (10) argues against this, 


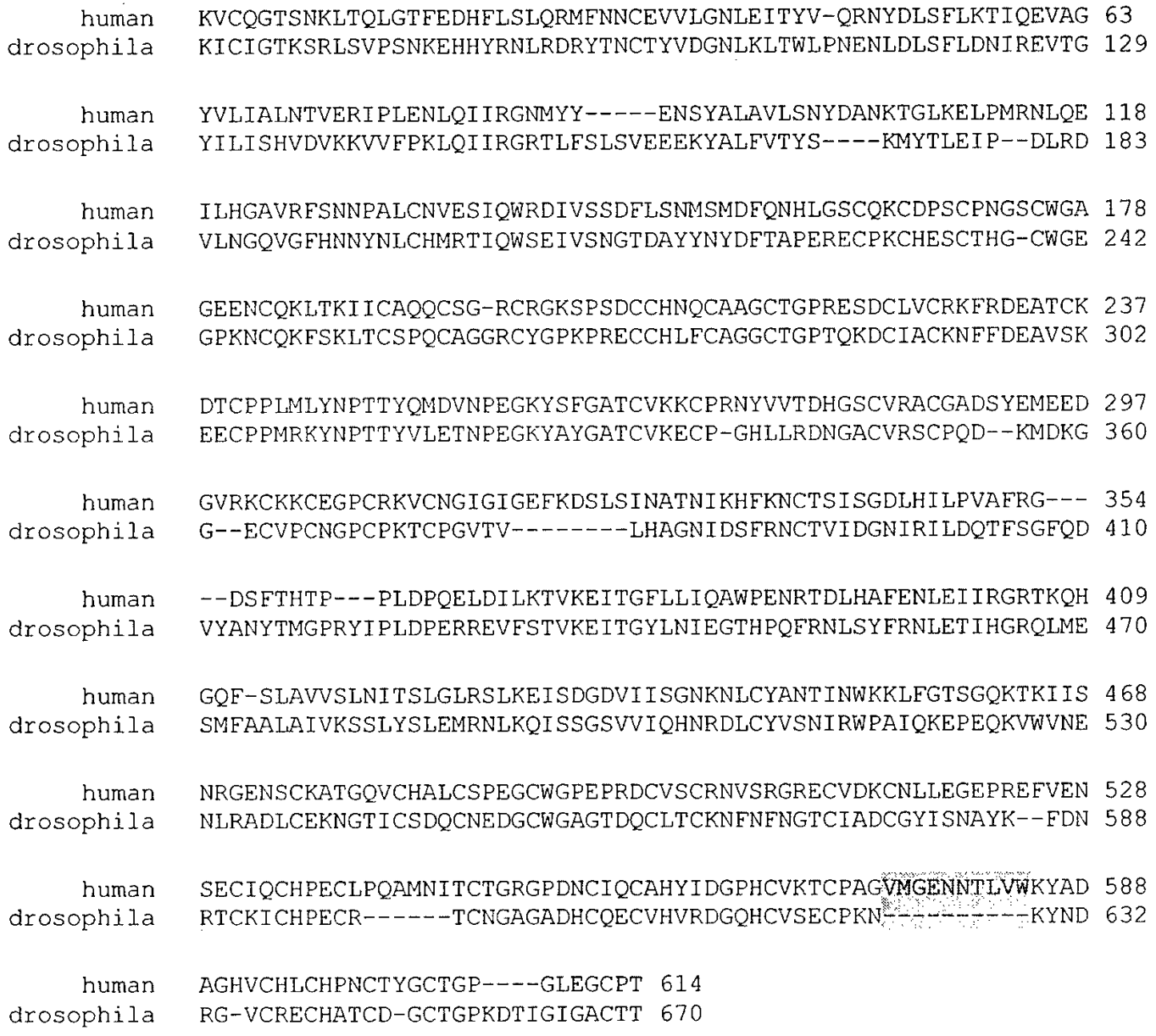

FIGURE 4-8

\section{Sequence alignment of human ErbB1 and DER ectodomains}

Presented is a portion of the sequence alignment of the human ErbB1 and Drosophila melanogaster EGF receptor (DER) extracellular domains. The human protein contains a 10-residue loop (known as the $\mathrm{C} 1_{\mathrm{Nd}}$ loop) that is missing in the fly protein (shaded), but is predicted to be important both in helping stabilize the intramolecular tether in the autoinhibited state as well as in making intermolecular contacts across the ligand-induced homodimer. The entire loop, from residues $\mathrm{Val}^{575}$ and $\operatorname{Trp}^{584}$, was deleted in our $\mathrm{C}_{\mathrm{IVd}}$ mutant. 
but direct experimental determination is required. Small angle X-ray scattering (SAXS) studies would also useful for determining the extent to which each protein exists in the tethered versus the extended conformations. SPR studies of the domain IV triple mutant suggest that $80-97 \%$ of the unliganded wild-type molecules adopt the autoinhibited conformation and $3-20 \%$ the extended conformation at equilibrium (10). As SAXS can provide information on the shape and size of a molecule in solution (28), this technique can be used to examine the effect of different mutations on driving the equilibrium between the tethered and extended conformations of the extracellular domain. This is particularly important for the domain II hexa-mutant. As described earlier in this section, we cannot fully assess the impact of the six point mutations in the dimerization arm without knowing if they affect intramolecular tethering as well as homodimerization. Future SAXS studies will allow us to gauge to what extent the mutant adopts the extended structure in the absence of ligand, which in turn will help us determine the energetic coupling of ligand-binding with homodimerization.

Further studies with mAb 806 should also be pursued in order to learn more about the region of domain II C-terminal to the dimerization arm (containing $\mathrm{Asp}^{279}$ and $\mathrm{His}^{280}$, along with the epitope for this antibody). For instance, it will be interesting to see if the D279A/H280A mutant displays differential binding to the antibody than the wild-type protein, which can be easily determined using SPR analysis. The effect of the antibody on ligand-binding will also be investigated. In addition, these mutations could be introduced into the context of the full-length receptor, allowing for insertion in the plasma membrane and Scatchard analysis of mAb 806 binding to cells expressing this mutant. 
Finally, the effect of the ectodomain mutations on ligand-induced signaling should be examined in a cellular context. Members of our lab are currently in the process of introducing the mutations into vectors encoding for the full-length receptor for expression in the Drosophila S2 cells (discussed in Chapter III). Expression of the mutated full-length receptors in the null background of the $\mathrm{S} 2$ cells will provide a useful system for monitoring alterations in cell-surface ligand-binding (by Scatchard analysis), as well as in ligand-induced downstream signaling events.

In summary, we have generated a set of structure-based mutants of the ErbB1 ectodomain that have allowed for a more detailed understanding of the mechanisms underlying ligand-induced receptor homodimerization. Our analysis indicates that while the original model is largely correct, there are additional important, structural rearrangements in domain II that are necessary for efficient ligand-binding and homodimerization. Our data indicate that ligand-binding is largely stabilized by two events - disruption of the intramolecular tether (allowing for extension of the entire molecule, bringing domains I and III in close proximity), and homodimerization of the receptor. Earlier studies have indicated similar findings $((9,10,17)$ for example), but our studies highlight new regions, such as the loop containing $\mathrm{Asp}^{279}$ and $\mathrm{His}^{280}$. Our studies also suggest that recent studies implicating domain IV as a major interface for mediating homodimerization (3), may be incorrect. However, it is clear that there is much work yet to be accomplished before we have a complete model of activation precisely detailing the energetic barriers and contributors to ligand-binding and dimerization.

The recent explosion of structural information on the ErbB receptors has made this a very exciting time for the field. The development of a model for the ligand- 
induced activation of the receptors increases the promise of the smarter design of targeted agents that would be useful in the clinical treatment of a wide variety of diseases. The identification of the dimerization arm in ErbB1 already reveals one such potent target. In addition, the crystal structures of ErbB3 and ErbB2 reveal similar domain II loops $(6,7,12)$, indicating that this structural feature may be important not only for ErbB1 homodimerization, but also for homodimerization of other ErbB receptors and even heterodimerization between the members of the family. It is hoped that the data outlined in this chapter will serve as the starting point for a wide range of future experiments which will ultimately lead to a better appreciation for and knowledge of this complex, but important, family of receptors.

1. Alroy, I., and Yarden, Y. (1997) FEBS Lett. 410, 83-86

2. Ausubel, F. M. (1987) Current Protocols in Molecular Biology, Greene Publishing Associates; J. Wiley, order fulfillment, Brooklyn, N. Y., Media, Pa.

3. Berezov, A., Chen, J., Liu, Q., Zhang, H. T., Greene, M. I., and Murali, R. (2002) J. Biol. Chem. 277, 28330-28339

4. Burgess, A. W., Cho, H. S., Eigenbrot, C., Ferguson, K. M., Garrett, T. P., Leahy, D. J., Lemmon, M. A., Sliwkowski, M. X., Ward, C. W., and Yokoyama, S. (2003) Mol. Cell 12, 541-552

5. Busam, K. J., Capodieci, P., Motzer, R., Kiehn, T., Phelan, D., and Halpern, A. C. (2001) Br. J. Dermatol. 144, 1169-1176

6. Cho, H. S., and Leahy, D. J. (2002) Science 297, 1330-1333

7. Cho, H. S., Mason, K., Ramyar, K. X., Stanley, A. M., Gabelli, S. B., Denney, D. W., Jr., and Leahy, D. J. (2003) Nature 421, 756-760

8. Dougall, W. C., Qian, X., Peterson, N. C., Miller, M. J., Samanta, A., and Greene, M. I. (1994) Oncogene 9, 2109-2123

9. Elleman, T. C., Domagala, T., McKern, N. M., Nerrie, M., Lonnqvist, B., Adams, T. E., Lewis, J., Lovrecz, G. O., Hoyne, P. A., Richards, K. M., Howlett, G. J., Rothacker, J., Jorissen, R. N., Lou, M., Garrett, T. P., Burgess, A. W., Nice, E. C., and Ward, C. W. (2001) Biochemistry 40, 8930-8939

10. Ferguson, K. M., Berger, M. B., Mendrola, J. M., Cho, H. S., Leahy, D. J., and Lemmon, M. A. (2003) Mol. Cell 11, 507-517

11. Ferguson, K. M., Darling, P. J., Mohan, M. J., Macatee, T. L., and Lemmon, M. A. (2000) EMBO J. 19, 4632-4643 
12. Garrett, T. P., McKern, N. M., Lou, M., Elleman, T. C., Adams, T. E., Lovrecz, G. O., Kofler, M., Jorissen, R. N., Nice, E. C., Burgess, A. W., and Ward, C. W. (2003) Mol. Cell 11, 495-505

13. Garrett, T. P., McKern, N. M., Lou, M., Elleman, T. C., Adams, T. E., Lovrecz, G. O., Zhu, H. J., Walker, F., Frenkel, M. J., Hoyne, P. A., Jorissen, R. N., Nice, E. C., Burgess, A. W., and Ward, C. W. (2002) Cell 110, 763-773

14. Horton, J. (2002) Cancer Control 9, 499-507

15. Hynes, N. E., and Stern, D. F. (1994) Biochim. Biophys. Acta. 1198, 165-184

16. Johns, T. G., Stockert, E., Ritter, G., Jungbluth, A. A., Huang, H. J., Cavenee, W. K., Smyth, F. E., Hall, C. M., Watson, N., Nice, E. C., Gullick, W. J., Old, L. J., Burgess, A. W., and Scott, A. M. (2002) Int. J. Cancer 98, 398-408

17. Jones, J. T., Akita, R. W., and Sliwkowski, M. X. (1999) FEBS Lett. 447, 227-231

18. Jungbluth, A. A., Stockert, E., Huang, H. J., Collins, V. P., Coplan, K., Iversen, K., Kolb, D., Johns, T. J., Scott, A. M., Gullick, W. J., Ritter, G., Cohen, L., Scanlan, M. J., Cavenee, W. K., and Old, L. J. (2003) Proc. Natl. Acad. Sci. U. S. A. 100, 639-644

19. Lemmon, M. A., Bu, Z., Ladbury, J. E., Zhou, M., Pinchasi, D., Lax, I., Engelman, D. M., and Schlessinger, J. (1997) EMBO J. 16, 281-294

20. Livneh, E., Glazer, L., Segal, D., Schlessinger, J., and Shilo, B. Z. (1985) Cell 40, 599-607

21. Luwor, R. B., Johns, T. G., Murone, C., Huang, H. J., Cavenee, W. K., Ritter, G., Old, L. J., Burgess, A. W., and Scott, A. M. (2001) Cancer Res. 61, 5355-5361

22. Mendelsohn, J., and Baselga, J. (2003) J. Clin. Oncol. 21, 2787-2799

23. Normanno, N., Bianco, C., De Luca, A., Maiello, M. R., and Salomon, D. S. (2003) Endocr. Relat. Cancer 10, 1-21

24. Ogiso, H., Ishitani, R., Nureki, O., Fukai, S., Yamanaka, M., Kim, J. H., Saito, K., Sakamoto, A., Inoue, M., Shirouzu, M., and Yokoyama, S. (2002) Cell 110, 775787

25. Schlessinger, J. (2000) Cell 103, 211-225

26. Schlessinger, J. (2002) Cell 110, 669-672

27. Schuck, P. (1997) Annu. Rev. Biophys. Biomol. Struct. 26, 541-566

28. Svergun, D. I., and Koch, M. H. (2002) Curr. Opin. Struct. Biol. 12, 654-660

29. Yarden, Y., and Sliwkowski, M. X. (2001) Nat. Rev. Mol. Cell. Biol. 2, 127-137 